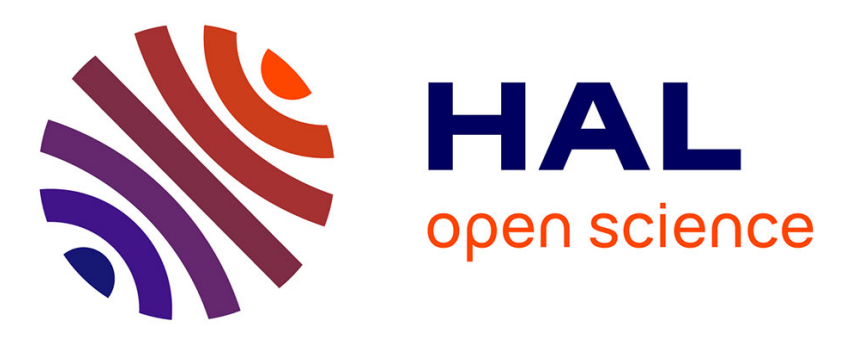

\title{
Modeling metal ion-humic substances complexation in highly saline conditions
}

\author{
Rémi M Marsac, Nidhu L Banik, Johannes L Lützenkirchen, Charlotte \\ Catrouillet, Christian M Marquardt, Karen H Johannesson
}

\section{To cite this version:}

Rémi M Marsac, Nidhu L Banik, Johannes L Lützenkirchen, Charlotte Catrouillet, Christian M Marquardt, et al.. Modeling metal ion-humic substances complexation in highly saline conditions. Applied Geochemistry, 2017, 79, pp.52-64. 10.1016/j.apgeochem.2017.02.004 . insu-01467504

\section{HAL Id: insu-01467504 https://hal-insu.archives-ouvertes.fr/insu-01467504}

Submitted on 14 Feb 2017

HAL is a multi-disciplinary open access archive for the deposit and dissemination of scientific research documents, whether they are published or not. The documents may come from teaching and research institutions in France or abroad, or from public or private research centers.
L'archive ouverte pluridisciplinaire HAL, est destinée au dépôt et à la diffusion de documents scientifiques de niveau recherche, publiés ou non, émanant des établissements d'enseignement et de recherche français ou étrangers, des laboratoires publics ou privés. 


\section{Accepted Manuscript}

Modeling metal ion-humic substances complexation in highly saline conditions

Rémi Marsac, Nidhu L. Banik, Johannes Lützenkirchen, Charlotte Catrouillet, Christian M. Marquardt, Karen H. Johannesson

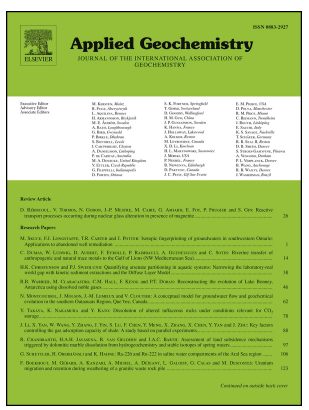

PII:

S0883-2927(16)30231-1

DOI:

10.1016/j.apgeochem.2017.02.004

Reference: $\quad$ AG 3821

To appear in: $\quad$ Applied Geochemistry

Received Date: 19 August 2016

Revised Date: 23 January 2017

Accepted Date: 1 February 2017

Please cite this article as: Marsac, R., Banik, N.L., Lützenkirchen, J., Catrouillet, C., Marquardt, C.M., Johannesson, K.H., Modeling metal ion-humic substances complexation in highly saline conditions, Applied Geochemistry (2017), doi: 10.1016/j.apgeochem.2017.02.004.

This is a PDF file of an unedited manuscript that has been accepted for publication. As a service to our customers we are providing this early version of the manuscript. The manuscript will undergo copyediting, typesetting, and review of the resulting proof before it is published in its final form. Please note that during the production process errors may be discovered which could affect the content, and all legal disclaimers that apply to the journal pertain. 
16 *Corresponding author: e-mail address: remi.marsac@univ-rennes1.fr

17 Tel: +332232353 56. Fax: +33223236090

$18{ }^{1}$ Géosciences Rennes UMR 6118, Université Rennes 1, CNRS, 35042 Rennes cedex, France.

$19{ }^{2}$ Institute for Nuclear Waste Disposal, Karlsruhe Institute of Technology, P.O. Box 3640, D-

2076021 Karlsruhe, Germany.

21 33RC-KARLSRUHE, G.II.6 - Nuclear Safeguards and Forensics, European Commission, 22 P.O.Box 2340, D-76125 Karlsruhe

$23{ }^{4}$ Department of Earth and Environmental Sciences, Tulane University, 6823 St. Charles Avenue, 24 New Orleans, LA 70118, USA. 


\section{Highlights:}

26 - Model VII and NICA-Donnan are tested at high ionic strength (I) using the SIT.

- For $I>1 \mathrm{~m}$, Model VII is applicable as a non-electrostatic model.

28

- No modification is needed for NICA-Donnan.

29

- Both models predict the effect of I on proton- and metal ion-humate (M-HA) binding.

- SIT parameters for simpler M-HA binding models vary with $\mathrm{pH}$ and metal loading. 
31 Abstract. Because highly saline groundwaters are found at potential repository sites for nuclear waste, geochemical models should predict the speciation of relevant radionuclides in brines, including their complexation with substances such as humic acids (HA). In this study, available experimental radionuclide-HA complexation data in high 1:1 background electrolyte solutions $\left(0.01<m_{\mathrm{NaCl} / \mathrm{NO}_{3} / \mathrm{ClO}_{4}}<4\right.$ molal, $\left.m\right)$ are reviewed. Discrepancies in the amplitude of ionic strength effects on radionuclide-HA complexation are observed, which might depend on the nature of the interacting radionuclide or on the origin of HA. However, significant differences in the experimental conditions and calculations applied to determine conditional metal ion-HA complexation constants hamper direct comparison between these datasets. To clarify whether metal ion-HA binding in saline solutions can be described, two sophisticated humic-ion binding models (Model VII and NICA-Donnan) are presently used. This is the first time that Model VII and NICA-Donnan are applied to predict metal ion-HA binding at high ionic strength $(I>1 \mathrm{~m})$. The advantage of these models, compared to more simple ones (e.g., the polyelectrolyte or the charge neutralization models), is that both electrostatic and chemical contributions to the overall metal ion-HA binding are explicitly taken into account. Model VII and NICA-Donnan are shown to produce very similar results. Trends in conditional metal ion-HA binding constants and in the maximum metal ion uptake by HA (e.g., the loading capacity) with $I$ agree with experiments. The present data evaluation suggests that most of the apparent discrepancies between various experimental datasets arise from differences in the experimental conditions. Both Model VII and NICA-Donnan predict that the specific ion interaction theory (SIT) parameters for metal ion-HA

51 systems, which are required for high ionic strength with more simple models, vary with $\mathrm{pH}$ and metal loading. Overall, Model VII and NICA-Donnan are able to account for various mechanisms involved in metal ion-HA complexation, including the metal loading effects and cation 
54 competition, and might be helpful predictive tools for performance safety assessment up to highly

55 saline conditions.

56 Keywords: humic, radionuclide, complexation, brine, saline, Model VII, NICA-Donnan, specific 57 ion interaction theory. 
Humic substances (HS) such as humic (HA) and fulvic (FA) acids are ubiquitous in

60 natural waters and form complexes with dissolved metal ions. They play a crucial role for metal

61 ion mobility and bioavailability in the environment. HS exhibit extreme complexity. The major

62 HS cation-binding groups are the carboxylic and phenolic groups (Ritchie and Perdue, 2003), but

63 less abundant softer Lewis bases (e.g., N- and S-containing groups) also contribute to cation-HS complexation (Tipping, 1998; Hesterberg et al., 2001). HS are macro-ions and electrostatic effects are relevant for their complexation properties. Moreover, several HS groups may bind a single cation, which either leads to a chelation effect (Martell and Hancock, 1996) or to the formation of a cation bridge between different organic molecules (e.g., Kunhi Mouvenchery et al., 2012). Hence, metal ions can form a large variety of complexes with HS, leading to apparent complexation constants that depend on $\mathrm{pH}$, ionic strength and metal ion/HS concentration ratio (i.e., the metal loading) including the presence of competing cations like $\mathrm{Ca}$ and $\mathrm{Mg}$. Substantial efforts have been made to determine thermodynamic metal ion-HS complexation constants and to develop predictive models for environmentally relevant conditions (e.g., Kim and Czerwinski, 1996; Benedetti et al., 1995; Tipping, 1998; Milne et al., 2001; 2003; Sasaki et al., 2008). Because of the complexity of HS, very different approaches have been proposed to describe the reaction between HS and metal ions.

The resulting metal ion-HS complexation models were developed for, and mainly applied to describe metal ion speciation under freshwater conditions, but were shown to be applicable for the more saline conditions that occur in estuaries and seawaters (e.g., Hiemstra and van Riemsdijk, 2006; Turner et al., 2008; Stockdale et al., 2011). Nonetheless, few studies have investigated metal ion-HS interactions under highly saline conditions, such as ionic strength $(I)$

81 exceeding that of seawater (i.e., $I>0.7 \mathrm{~m}$ ). The latter conditions are relevant with regard to the 

safety of nuclear waste disposal in rock salt formationsor in specific clay formations. For example, deep waters in the Jurassic and lower Cretaceaous clay rock formations in Northern Germany may contain salt concentrations as high as about 4 M (Mühlenberg et al., 1997). Sedimentary rocks currently investigated in Canada are in contact with brine solutions up to 6.5 M (Fritz and Frape, 1982). Although high ionic strength commonly leads to the coagulation of HS, this process has been shown to be incomplete in many cases and non-negligible amounts of dissolved HS were reported to persist (Wall and Choppin, 2003), which can react with dissolved metal ions.

Most of the radionuclide-HS complexation studies in saline solutions focused on HA. Because few data for FA exist, only HA binding properties at high ionic strength are discussed herein. Generally, at constant $\mathrm{pH}$, the apparent radionuclide-HA complexation constants in monovalent background electrolyte solutions (e.g., $\mathrm{NaCl}$ or $\mathrm{NaClO}_{4}$ ) decrease with increasing ionic strength from very dilute aqueous solutions up to 1 molal $\left(\mathrm{mol} \mathrm{kg}^{-1}\right.$, hereafter denoted $\left.m\right)$. However, different binding behaviors are observed for $I>1 \mathrm{~m}$. Specifically, $\mathrm{UO}_{2}{ }^{2+}$ - and $\mathrm{Pu}^{4+}-\mathrm{HA}$ complexation constants increase with increasing ionic strength (Labonne-Wall et al., 1999; Szabò et al., 2010), whereas $\mathrm{Co}^{2+}-\mathrm{HA}$ complexation does not vary substantially, and $\mathrm{Ni}^{2+}-\mathrm{HA}$ complexation slightly decreases (Kurk and Choppin, 2000) with increasing ionic strength. Although data from Czerwinski et al. (1996) and Wall et al. (2002) consistently show increasing $\mathrm{Am}^{3+} / \mathrm{Cm}^{3+}$-HA binding with increasing I, Czerwinski et al. (1996) observed minor variation in complexation constant values with $I$. This led them to propose an average value (with standard variation of $\pm 0.14 \log$ units) for the entire range of $I$ investigated, which contrasts with Wall et al. (2002) where much larger variations were reported (about $3 \log$ units). Furthermore, for $1 \leq I \leq$ $3.5 \mathrm{~m}$, the maximum amount of radionuclide that is experimentally found to bind to HA (e.g., the so called loading capacity in the charge neutralization model) was shown to decrease with 
106 increasing $I$ for trivalent actinides (Czerwinski et al., 1996), whereas it remained constant in the 107 case of $\mathrm{Pu}(\mathrm{IV})$ (Szabò et al., 2010). All these discrepancies might be indicative of conformational 108 changes in saline solutions, which would depend on the nature of the interacting radionuclide as 109 well as on the origin of HA. However, significant differences exist in the experimental conditions 110 and calculations applied to determine conditional metal ion-HA complexation constants between 111 these different studies, which complicates data comparison. Some studies were conducted in non112 complexing background electrolyte solutions $\left(\mathrm{NaClO}_{4}\right.$; Czerwinski et al., 1996; Szabò et al., 113 2010). High $\left[\mathrm{Cl}^{-}\right]$is environmentally relevant (as opposed to high $\left[\mathrm{ClO}_{4}^{-}\right]$), but metal ions can 114 bind $\mathrm{Cl}^{-}$, which may affect the determination of radionuclide-HA complexation constants. 115 Complexation data for $\mathrm{UO}_{2}{ }^{2+}$ - and $\mathrm{Am}^{3+}$-HA binding from Labonne-Wall et al. (1999) and Wall 116 et al. (2002) were obtained in acetate buffers under ambient (air) atmosphere. Like many ligands, 117 acetate and carbonate form aqueous complexes with $\mathrm{UO}_{2}{ }^{2+}$ and $\mathrm{Am}^{3+}$ and can compete with HA. 118 Experiments were conducted at different radionuclide-to-HA concentration ratios, which might 119 also affect HA charge and conformation. Finally, $\mathrm{pH}$ measurement is non-trivial in saline 120 solutions. More specifically, "constant $\mathrm{pH}$ values" can refer to constant proton activity $(\mathrm{pH}=-$ $121 \log a_{H^{+}}$; Szabò et al., 2010), proton molality $\left(\mathrm{pH}_{\mathrm{m}}=-\log m_{H^{+}}\right.$; Czerwinski et al., 1996; 122 Labonne-Wall et al., 1999; Wall et al., 2002), or constant experimental values, as read on the pH123 meter $\left(\mathrm{pH}_{\text {exp }}\right.$; Kurk and Choppin, 2000; where the $\mathrm{pH}_{\exp }-\mathrm{pH}_{\mathrm{m}}$ relationship is provided). Deviation 124 between $\mathrm{pH}, \mathrm{pH}_{\mathrm{m}}$ and $\mathrm{pH}_{\exp }$ as affected by $I$ may also hamper comparison between different 125 datasets.

Available radionuclide-HA complexation data have been analyzed using relatively simple 127 models such as the Polyelectrolyte Model (PM; Torres and Choppin, 1984) or the Charge 128 Neutralization Model (CNM; Kim and Czerwinski, 1996). These models can be conveniently 129 included in the speciation codes used for performance safety assessment. Within these models, 
130 binding parameters may vary with $\mathrm{pH}$ and $I$. High salt levels require an appropriate treatment of

131 activity coefficients for aqueous species in geochemical models, such as application of specific

132 ion interaction theory (SIT; Ciavatta, 1980). Metal-HA complexation constants can also be

133 extrapolated to $I=0$ using SIT, when considering HA as a solute. However, due to HA

134 complexity, SIT parameters are no more than adjustable parameters and their values have no

135 clear physical significance according to the original authors (Czerwinski et al., 1996; Szabò et al.,

136 2010). Given the differences in the experimental conditions between previous radionuclide-HA

137 complexation studies and the different calculations applied for the determination of metal-HA

138 complexation constants (e.g., with the CNM or the PM), it is difficult to evaluate how SIT

139 parameters would evolve with changing metal ion concentrations and physico-chemical

140 conditions.

141 More sophisticated models exist, such as the humic ion binding Model VII (Tipping et al.,

142 2011), or its previous versions (Models V/VI: Tipping and Hurley, 1992; Tipping, 1998), and the

143 NICA-Donnan model (Kinniburgh et al., 1996; Koopal et al., 2005). The description of HA

144 properties relies on several assumptions, and the various models include a more or less detailed

145 description of metal ion-HA interaction. In particular, the electrostatic and chemical contributions

146 to the overall metal ion-HA binding are separated in the models. This is a major advantage for

147 understanding metal ion-HA binding in saline solutions, because ionic strength is expected to

148 more strongly affect electrostatic than chemical binding properties of HA. Unfortunately, as

149 pointed out by Tipping (1998), the electrostatic approach included in Models V/VI/VII is

150 unlikely to be applicable for $I>1 \mathrm{~m}$. In contrast, NICA-Donnan equations seem to be applicable

151 in highly saline conditions (up to $2 \mathrm{M}$ ), as shown for HA proton titration data (Benedetti et al.,

152 1996), but, to our knowledge, it has never been tested for metal ion-HA complexation data. 
In the following, we evaluate the applicability of Model VII and the NICA-Donnan model

154 for saline aqueous solutions, focusing on the concomitant electrostatic approaches. The following

155 analysis involves close inspection of the model equations in conjunction with comparisons of 156 simulated and experimental HA proton titration and radionuclide complexation data. The 157 mechanisms responsible for the effect of ionic strength on cation-HA complexation are also 158 discussed within the context of the assumptions inherent to Model VII and NICA-Donnan.

159 Finally, the impact of the physico-chemical conditions on the experimental determination of SIT 160 parameters for more simple cation-HA models is discussed.

\section{Theoretical background}

163

164

165

166

\subsection{Aqueous speciation calculations and codes}

Ionic strength $(I)$ affects the activity of dissolved ions in solution, which must be accounted for, for instance, when extrapolating formation constants to hypothetical infinite dilution condition (i.e., for $I=0 \mathrm{~m}$ ). In the present study, activity coefficients $(\gamma)$ are calculated according to the specific ion interaction theory (SIT; Ciavatta, 1980). SIT is generally considered valid for ionic strengths up to $3-4 \mathrm{~m}$. At $25^{\circ} \mathrm{C}$, activity coefficients for an aqueous species $i$ with a charge $z_{i}$ are calculated as follows:

$\log \gamma_{i}=-z_{i}{ }^{2} \frac{0.509 \times \sqrt{I}}{1+1.5 \sqrt{I}}+\sum_{k} \varepsilon(i, k) \times m_{k}=-z_{i}^{2} D+\sum_{k} \varepsilon(i, k) \times m_{k}$

where D is the Debye-Hückel term used in SIT, $m_{k}$ is the molality of the aqueous species $k$ (mol $\left.\mathrm{kg}^{-1}\right)$, and $\varepsilon(\mathrm{i}, \mathrm{k})$ is the specific ion interaction coefficient between species $i$ and $k\left(\mathrm{~kg} \mathrm{~mol}^{-1}\right)$.

In the present study, we use PHREEQC (version 2; Parkhurst and Appelo, 1999) to model cation-HA binding with Model VII. The NICA-Donnan model is not implemented in PHREEQC yet, which will require future modification of PHREEQC code. Therefore, Visual MINTEQ 
175 (version 3.0; Gustafsson, 2012) is used to model cation-HA binding with NICA-Donnan. The SIT

176 database provided with each code is used (which corresponds to ThermoChimie v.7.b in

177 PHREEQC). Unless mentioned in this study, the same thermodynamic constants and SIT

178 parameters were selected throughout. The metastability of $\mathrm{ClO}_{4}^{-}$, sometimes used as background

179 anion, is avoided in the models by defining perchlorate as a master species. The Pitzer approach

180 (Pitzer, 1991) can be applied to calculate activity coefficients for aqueous ions in even more

181 concentrated media than appropriate for SIT, which would be more relevant for brine solutions.

182 However, in the present study, the SIT was chosen: (i) for the sake of simplicity, as it is

183 approximately equivalent to a simplified Pitzer model (Grenthe et al., 1993); (ii) because most of

184 the thermodynamic data are taken from the NEA database (Guillaumont et al., 2003), which

185 recommends the use of SIT; and (iii) because Pitzer equations are implemented in PHREEQC but

186 not in Visual MINTEQ, the NICA-Donnan model cannot be tested yet in combination with the

187 Pitzer model.

188 Experimental $\mathrm{pH}$ measurements $\left(\mathrm{pH}_{\exp }\right)$ are affected by the background electrolyte

189 concentration under saline conditions (e.g., Altmaier et al., 2003), and appropriate calibrations

190 are necessary to relate empirical $\mathrm{pH}_{\mathrm{exp}}$ to the molality of the proton $\left(\mathrm{pH}_{\mathrm{m}}=-\log m_{H^{+}}\right)$. The

191 deviation between $\mathrm{pH}_{\mathrm{exp}}$ and $\mathrm{pH}_{\mathrm{m}}$ increases with increasing ionic strength such that $\mathrm{pH}_{\exp }<\mathrm{pH}_{\mathrm{m}}$

192 for concentrated electrolytes. The $\mathrm{pH}\left(=-\log a_{H^{+}}\right)$, which is a master variable and hence required

193 by speciation codes, can be determined from $\mathrm{pH}_{\mathrm{m}}$ and calculated $\gamma_{H^{+}}$values. In this study, SIT is

194 used to calculate $\mathrm{pH}$.

195

196 
$M+H A=M H A$

201 and the corresponding conditional stability constant is

${ }^{H A} \beta=\frac{[M H A]}{[M]_{f}[H A]_{f}}$

202 Various approaches can be found in the literature to determine ${ }^{\mathrm{HA}} \beta$ values. Therefore, it is not

203 possible to directly compare ${ }^{\mathrm{HA}} \beta$ values reported in separate M-HA complexation studies unless

204 the same calculations were made or appropriate corrections are applied. The differences arise

205 from the various possibilities for defining $[\mathrm{M}]_{\mathrm{f}}$ or $[\mathrm{HA}]_{\mathrm{f}}$ in eq. 3. For example, $[\mathrm{M}]_{\mathrm{f}}$ may refer to

206 (i) the total dissolved metal ion concentration at equilibrium (noted $[\mathrm{M}]_{\text {tot, } \mathrm{f}}$ in the following),

complexation constants referring to the total dissolved metal ion concentration and to the aquo-

210 ion will be denoted ${ }^{\mathrm{HA}} \beta(\mathrm{M})$ and ${ }^{\mathrm{HA}} \beta\left(\mathrm{M}^{\mathrm{z}+}\right)$, respectively. $\left[\mathrm{M}^{\mathrm{Zt}}\right]_{\mathrm{f}}$ can be calculated by dividing the

$211[\mathrm{M}]_{\text {tot, } \mathrm{f}}$ value by the side reaction coefficient $\left(\alpha_{M} ;\right.$ Ringböm, 1963):

$\alpha_{M}=1+\sum_{h} \frac{{ }^{*} \beta_{h}}{m_{H^{+}}^{h}}+\sum_{l} \beta_{l} \times m_{L}^{l}$.

212 Here, ${ }^{*} \beta_{\mathrm{h}}$ are the hydrolysis constants, $\mathrm{L}$ is a ligand, $\beta_{l}$ are the formation constants for $\mathrm{M}(\mathrm{L})_{l}$

213 complexes and $m_{H^{+}}$and $m_{L}$ refer to the molalities of $\mathrm{H}^{+}$and $\mathrm{L}$. In eq. $4, * \beta_{\mathrm{h}}$ and $\beta_{l}$ are

214 conditional constants, valid at a given ionic strength. Possible ternary complexes (i.e., involving a 
215 metal ion and two different ligands) or polynuclear species are not included in eq. 4 for the sake

216 of simplicity in the present text, but they must be taken into account in the calculations.

The definition of $[\mathrm{HA}]_{\mathrm{f}}$ (eq. 3) also depends on the humic-ion binding model considered.

218 In the present study, the notation of Marquardt and Kim (1998) is used for the different ${ }^{\mathrm{HA}} \beta$

219 (namely, ${ }^{\mathrm{HA}} \mathrm{K},{ }^{\mathrm{HA}} \beta_{\mathrm{LC}}$ or ${ }^{\mathrm{HA}} \beta_{\alpha}$, as defined below). HA site density, commonly corresponding to the 220 proton exchange capacity of HA (PEC, in eq $\left.\mathrm{g}(\mathrm{HA})^{-1}\right)$, can be taken into account to determine the 221 total HA site concentration $\left([\mathrm{HA}]_{\mathrm{tot}}\right.$, in eq $\left.\mathrm{kg}\left(\mathrm{H}_{2} \mathrm{O}\right)^{-1}\right)$. The corresponding M-HA complexation 222 constant, denoted ${ }^{\mathrm{HA}} \mathrm{K}$, can be calculated considering that:

$[H A]_{f}=[H A]_{t o t}-[M H A]$

223 where ${ }^{\mathrm{HA}} \mathrm{K}$ varies with $\mathrm{pH}$, ionic strength, metal loading, etc.

224 Competition between the metal ion and $\mathrm{H}^{+}$can be included via the degree of 225 deprotonation $\left(\alpha_{H A}\right)$ in order to suppress the dependence of the M-HA complexation constant on $226 \mathrm{pH}$ :

$[H A]_{f}=[H A]_{t o t} \times \alpha_{H A}-[M H A]$.

227 The concomitant complexation constant is noted ${ }^{\mathrm{HA}} \beta_{\alpha}$ and refers to the Polyelectrolyte Model 228 (PM; Torres and Choppin, 1984). The degree of deprotonation, $\alpha_{H A}$, is experimentally 229 determined by proton titration and depends on both $\mathrm{pH}$ and ionic strength. Another approach is to consider the effective amount of binding sites at a given $\mathrm{pH}$ and $I$.

231 Here, the aim is to suppress the dependence of the M-HA complexation constant on both $\mathrm{pH}$ and 232 HA site saturation at high metal loading. In a Pu(IV)-HA study, Szabó et al. (2010) determined 233 the maximum complexing capacity $\left(\mathrm{B}_{\max }\right.$, in $\left.\mathrm{mol} \mathrm{g}^{-1}\right)$ of $\mathrm{HA}$ immobilized on silica gel (19.9 $\mathrm{mg}$ $\left.234 \mathrm{HA} \mathrm{g}^{-1}\right)$, associated with a complexation constant denoted ${ }^{\mathrm{HA}} \beta\left(\mathrm{Pu}^{4+}\right)$ :

$[H A]_{f}=B_{\max }-[P u H A]$ 
235 where $\mathrm{B}_{\max }$ and ${ }^{\mathrm{HA}} \beta\left(\mathrm{Pu}^{4+}\right)$ are determined by analyzing $\mathrm{SiO}_{2}-\mathrm{HA}-\mathrm{Pu}$ binding isotherms with a

236 Langmuir-type equation.

237 The effective amount of binding considered in the Charge Neutralization Model (CNM;

238 Kim and Czerwinski, 1996) is the "loading capacity" (LC, generally in mol g ${ }^{-1}$ ). For this model, it

239 is assumed that the total amount of HA sites that is available to neutralize the metal depends on

240 the metal charge ( $z$ ). In the CNM, the free HA site concentration is defined as:

$[H A]_{f}=[H A]_{t o t} \times L C / z-[M H A]$

241 The corresponding M-HA complexation constant is noted ${ }^{\mathrm{HA}} \beta_{\mathrm{LC}}$.

\subsection{Humic-ion binding models NICA-Donnan and Model VII}

\subsubsection{Chemical part of the models}

NICA-Donnan and Model VII have been described in several publications (e.g., Koopal et

al., 2005; Tipping et al. 2011). Because the effect of the ionic strength is taken into account through the electrostatic part of these models, the chemical part is only briefly discussed here.

248 Cation-HA complexation (including $\mathrm{H}^{+}$) in NICA-Donnan and Model VII follows identical 249 reaction equations (eq. 2). Additional equations are used to account for HA heterogeneity. NICA-

250 Donnan describes HA heterogeneity by a continuous affinity distribution for the interaction 251 between a cation and HA, whereas Model VII considers a large number of binding sites with 252 different but discrete affinities for the cation. The chemical cation-HA binding parts of these 253 models aim at describing the overall cation-HA complexation (e.g., expressed as a $\log { }^{\mathrm{HA}} \mathrm{K}$ value) as a function of $\mathrm{pH}$, cation to HA concentration ratio (or "metal loading"), and take into account cation competition with a limited number of parameters. The latter parameters are "intrinsic"

256 because they do not vary with the physico-chemical conditions. However, parameters usually 257 vary with the type of HA, including origin or composition. Generic parameters for a wide range 
258 of metal ions and HAs were determined for NICA-Donnan (Milne et al., 2001; 2003) and Model

259 VII (Tipping et al., 2011) by fitting experimental datasets. These generic parameters capture

260 "average" HA behavior, and will be used as such in this study. Consequently, the present work

261 does not aim at discussing the capability of the generic parameters to precisely simulate a given

262 dataset (i.e., no parameter optimization is made). Rather the capability of NICA-Donnan and

263 Model VII to predict variations in apparent cation-HA binding constants with the ionic strength

264 will be discussed (e.g., trends in $\log { }^{\mathrm{HA}} \mathrm{K}$ versus $I$ ).

265 It is important to note that, in NICA-Donnan and Model VII, $\mathrm{Na}^{+}$is not considered to

266 bind specifically to HA unlike $\mathrm{Ca}^{2+}$ or $\mathrm{Mg}^{2+}$, which complex with $\mathrm{HA}$ in solution. Therefore, for

267 high 1:1 Na-containing background electrolyte solution (e.g. $\mathrm{NaCl} / \mathrm{NO}_{3} / \mathrm{ClO}_{4}$ ), $\mathrm{Na}^{+}$is considered

268 to control the ionic strength and to affect other metal ion complexation by HA only via

269 electrostatic effects.

\subsubsection{Electrostatic models}

HAs are large and negatively charged polyelectrolytes. This leads to an accumulation of

273 cations in the vicinity of HA binding sites. Electrostatic models aim at converting the dissolved

274 cation concentration in the bulk solution $\left([\mathrm{C}]_{\mathrm{i}}\right)$ to a local dissolved cation concentration $\left([\mathrm{C}]_{\text {loc }, \mathrm{i}}\right)$

275 that occurs adjacent to the HA site. To accomplish this, the electrostatic potential of HA particles

$276(\Psi$, in $\mathrm{V})$ is computed using a Boltzmann factor:

$277 \quad[C]_{l o c, i}=[C]_{i} \times \exp \left(-z_{i} F \Psi / R T\right)$

278 Here, $z_{i}$ is the charge of the cation, $T$ is absolute temperature, $F$ is the Faraday constant and $R$ is 279 the gas constant.

Within the NICA-Donnan framework, HAs are considered as permeable spheres. 281 Counter-ions are accumulated in a Donnan phase. The electrostatic potential $\left(\Psi_{\mathrm{D}}\right)$ is constant 
282 inside the Donnan volume and equals zero outside (i.e., in the bulk solution). The Donnan

283 volume $\left(\mathrm{V}_{\mathrm{D}}\right.$, in $\left.\mathrm{L} \mathrm{kg}(\mathrm{HA})^{-1}\right)$ is calculated as follows:

$284 \log V_{D}=b(1-\log I)-1$

285 The parameter $b$ is adjusted by fitting acid-base titration experiments at varying $I$ and depends on

286 the type of HA (origin, composition, etc). In the Donnan volume, the negative charge of HA $(Q)$

287 is neutralized by counterions:

$288 \frac{Q}{V_{D}}+\sum_{i} z_{i}\left([C]_{D, i}-[C]_{i}\right)=0$

289 where $\mathrm{C}_{\mathrm{D}, \mathrm{i}}$ and $\mathrm{C}_{\mathrm{i}}$ refer to the concentration of the ion $i$ with a charge $z_{i}$ in the Donnan phase and

290 in the bulk solution, respectively. The activity of the ion in the Donnan phase is required for 291 calculation of the specific binding.

Within the Model VII framework, HA molecules are considered as impermeable spheres.

293 Since the conceptualization of HA particles and the numerical treatment of the electrostatic

294 effects resemble a surface complexation model (e.g., see the present implementation of Model

295 VII in PHREEQC in the following section), we will denote the electrostatic potential $\Psi_{0}$,

296 similarly to the surface potential of minerals. The electrostatic correction is an empirical equation

297 that mimics the Boltzmann factor:

$298 \exp \left(-F \Psi_{0} /(R T)\right)=\exp (-2 P Q \log (I))$

299 where $I$ is the ionic strength $\left(\mathrm{mol} \mathrm{L}^{-1}\right), \mathrm{P}$ is an adjustable parameter (generally $-400<\mathrm{P}<-100$ for $300 \mathrm{HA}$ ) and $Q$ is the net humic acid charge (eq $\mathrm{g}^{-1}$ ). In $\mathrm{NaCl} / \mathrm{NO}_{3} / \mathrm{ClO}_{4}$ background electrolytes, the 301 molality and molarity scales do not significantly differ for $I \leq 1 \mathrm{M}$ (or $m$ ). The molality scale is 302 used to extrapolate the model to high $I$. A Donnan model is also used in the original version of 303 Model VII, but it only accounts for counter-ion accumulation (i.e., to calculate the amount of ion 304 bound to HA in a non-specific manner) and has no effect on electrostatics, in contrast to the 305 NICA-Donnan model. Because in Model VII, HA is considered to be an impermeable sphere of 
radius $r$, the Donnan volume is a layer at the surface of the sphere, with a thickness equal to the

307 Debye length $\left(\kappa^{-1}=\left(3.29 \times 10^{9} \times I^{1 / 2}\right)^{-1}\right.$; in meters, $I$ in mol $\mathrm{L}^{-1}$ and at $\left.25^{\circ} \mathrm{C}\right)$. With the molar mass

308 and the radius of HA $\left(15000 \mathrm{~g} \mathrm{~mol}^{-1} ; 1.72 \mathrm{~nm}\right)$ inherent to Model VII, the surface area of HA

$309\left(\mathrm{~A}_{\mathrm{HA}}\right)$ equals $1500 \mathrm{~m}^{2} \mathrm{~g}^{-1}$. Hence, the Donnan volume in Model VII equals $\mathrm{A}_{\mathrm{HA}} \times \mathrm{K}^{-1}$ (in $\mathrm{m}^{3} \mathrm{~g}^{-1}$ ).

310 Unfortunately, the "-donnan" keyword cannot be used with SIT and Pitzer options in PHREEQC.

311 It can only be used with other databases, which do not involve SIT or Pitzer models (e.g. which

312 use Davies or Debye-Hückel equations to calculate activity coefficients). However, during

313 preliminary tests, we found very little effect of these calculations on the overall cation-HA

314 binding (see Fig. S2), especially at high $I$ where the Donnan volume drastically shrinks.

315 Therefore, this option is not used in the present study, that is, counter-ion accumulation is 316 neglected.

\subsubsection{Implementation of Model VII in PHREEQC}

The complete Model VII chemical reaction database, described in Tipping et al. (2011), was previously included in PHREEQC by Marsac et al. (2014) and is used in this study. In the supporting information, a file that can be used to modify Model VII chemical reaction database (e.g., to include other cations or to change binding parameters) and an example of PHREEC input file are given. convert this empirical electrostatic humic ion-binding model into the diffuse layer model (DLM) formalism (Appelo and Postma, 2005; Liu et al., 2008; Marsac et al., 2011, 2014; Catrouillet et al., 2014). Such a conversion requires the calculation of a surface area $\left(\mathrm{A}_{\mathrm{HA}}\right)$ that depends on the

328 ionic strength. Similar computations have been performed for polyelectrolytes such as polyacrylic acid (Lützenkirchen et al., 2011). Such approaches result in physically unreasonable 
330 surface areas (above $10^{4} \mathrm{~m}^{2} \mathrm{~g}^{-1}$ ) (Appelo and Postma, 2005; Liu et al., 2008; Lützenkirchen et al.,

331 2011; Marsac et al., 2011, 2014; Catrouillet et al., 2014). Hence, we suggest the use of the 332 constant capacitance model (CCM) might be a better choice (Catrouillet et al., 2015). For the

$333 \mathrm{CCM}$, the capacitance $\left(\mathrm{C}_{1}\right.$, in $\left.\mathrm{F} \mathrm{m}^{-2}\right)$ evolves with $\log I$ in the case of minerals (Lützenkirchen, 334 1999), and a log I-term is also found in the empirical electrostatic model in Model VII (eq. 12).

335 Specifically, the CCM employs a linear relationship between the charge density at the surface $\left(\sigma_{0}\right.$, 336 in $\left.\mathrm{C} \mathrm{m}^{-2}\right)$ and the surface potential $\left(\Psi_{0}\right.$, in $\left.\mathrm{V}\right)$ :

$337 \sigma_{0}=C_{1} \times \Psi_{0}$.

338 Combination of equations 12 and 13 gives:

$339 C_{1}=F^{2} \times\left(2 R T P A_{H A} \log (I)\right)^{-1}$.

340 Therefore, using the CCM leads to an expression for $\mathrm{C}_{1}$ that does not depend on the $\mathrm{pH}$. Given 341 the surface area of HA in Model VII $\left(\mathrm{A}_{\mathrm{HA}}=1500 \mathrm{~m}^{2} \mathrm{~g}^{-1}\right)$, the range of $\mathrm{C}_{1}$ values found for $I<1$ $342 m$ corresponds to that commonly reported for minerals $\left(0.5<\mathrm{C}_{1}<10 \mathrm{~F} \mathrm{~m}^{-2}\right.$; Lützenkirchen, 343 1999). Although the CCM is not implemented in PHREEQC, it can be used by applying 344 appropriate corrections to the three plane model (TPM) in PHREEQC. Details are given in 345 supporting information.

\section{Results and Discussion}

\subsection{Proton titration in saline solutions}

Although proton titrations of HA are rarely carried out for $I>1 \mathrm{~m}$, a number of critical

350 studies do exist. Kurk and Choppin (2000) and Laszak and Choppin (2001) performed proton 351 titrations of $\mathrm{HA}$ at $I=0.1,0.3,1,3$ and $5 \mathrm{~m}(\mathrm{NaCl})$, and calculated apparent dissociation constants $\left(\mathrm{pK}_{\mathrm{a}}\right)$ for $\mathrm{HA}$ considering two acidic groups. They found that $\mathrm{pK}_{\mathrm{a}}$ variation was 353 insignificant $( \pm 0.1)$ within this range of ionic strengths. Marinsky et al. (1982) reported similar 
354 observations for ionic strength between 0.2 and $2 \mathrm{M} \mathrm{NaNO}_{3}$. Furthermore, the charging curves

355 for HA versus the $\mathrm{pH}_{\mathrm{m}}$ reported by Maes et al. (1992) exhibited only slight differences between 1 356 and $3 \mathrm{M} \mathrm{NaClO}_{4}$. Van Dijk (1959) observed a shift in the titration curves to lower "pH" for $I$ 357 increasing from 0.02 to $2 \mathrm{M} \mathrm{NaCl}$ but mentioned no $\mathrm{pH}$-correction. This effect is qualitatively 358 consistent with the increased deviation between $\mathrm{pH}_{\exp }-\mathrm{pH}_{\mathrm{m}}$ with increasing $I\left(\mathrm{pH}_{\exp }<\mathrm{pH}_{\mathrm{m}}\right)$ that is 359 commonly observed (e.g., Kurk and Choppin, 2000; Altmaier et al., 2003). The surface of 360 biological cells, such as the seaweed Ulva lattuca, can be considered as a polyelectrolyte, and the 361 cation sorption properties onto $U$. lattuca can be treated with the models applied to HA (e.g. 362 Turner et al., 2008). Surface acid-base properties of such biosorbents show very little influence of $363 I$ above $1 m$ (e.g. Rey-Castro et al., 2003; Schijf and Ebling, 2010).

The apparent $\mathrm{pK}_{\mathrm{a}}$ of one HA site at a given ionic strength $\left(\mathrm{pK}_{\mathrm{a}}(\mathrm{I})\right)$, which is obtained 365 experimentally, can be written as follows:

$p K_{a}(I)=-\log \frac{\left[H^{+}\right]\left[H A^{-}\right]}{[H H A]}=p K_{a}(I=0)+\log \left(\gamma_{H^{+}}\right)-F \Psi /(R T \ln (10))$

366 According to eq. 15, the observed small dependence of conditional HA proton dissociation 367 constants on $I$ for highly saline conditions $(I>1 \mathrm{~m})$ might occur (i) due to small dependencies of 368 both $\Psi$ and $\gamma_{H^{+}}$on $I$ or (ii) compensation of the effects of $I$ on $\Psi$ and $\gamma_{H^{+}}$. Figure 1a compares the 369 effect of $I$ on $\Psi_{0}$ (for Model VII) and $\Psi_{D}$ (for NICA-Donnan) at constant proton activity $(\mathrm{pH}=$ 370 5.5). As stated by Tipping (1998), Model VI is unlikely to find application at ionic strengths 371 higher than $I=1 \mathrm{~m}$, because of the electrostatic model (the same is true for Model VII). When the 372 electrostatic term is translated to the CCM formalism (e.g., to be used in PHREEQC; eq. 14), and 373 for the case when $I$ increases to $1 m, \mathrm{C}_{1}$ tends to infinity and the model becomes essentially non374 electrostatic $\left(\Psi_{0}=0\right)$. When $I>1 \mathrm{~m}, \mathrm{C}_{1}$ is negative, which is physically unrealistic, 
demonstrating that Model VII cannot be used with PHREEQC when $I>1 \mathrm{~m}$ (except by suppressing the electrostatic term), consistent with the conclusion of Tipping (1998).

Benedetti et al. (1996) previously demonstrated the capability of NICA-Donnan to simulate HA charging curves versus $\mathrm{pH}$ in highly saline conditions (up to $2 \mathrm{M}$ ). In this case $\Psi_{D}$ increases with $I$ and only small variation in $\Psi_{D}$ can be seen for $I>1 \mathrm{~m}$ (Fig. 1a). The NICA-

Donnan model's inherent electrostatic contribution in cation-HA binding is approximately constant $\left(-60 \mathrm{mV} \leq \Psi_{D} \leq-40 \mathrm{mV}\right)$ for $I>1 \mathrm{~m}$, and only a small dependence of apparent $\mathrm{pK}_{\mathrm{a}}$ values (i.e., corrected for the activity coefficient effect) on $\Psi_{D}$ is predicted. This is because the Donnan volume is small for $I>1 \mathrm{~m}$ and only slightly shrinks when $I$ further increases. Interestingly, the amplitude of the variation in $\Psi$ is similar for both models when using the generic parameters: $\Psi_{D} \approx \Psi_{0}-60 \mathrm{mV}$ for $I<1 \mathrm{~m}$ and $\mathrm{pH}=5.5$, as highlighted in Figure 1a. Therefore, by suppressing the electrostatics in Model VII for $I \geq 1 \mathrm{~m}$, we produce a comparable effect of $I$ on cation-HA binding constants as in NICA-Donnan. This leads to a simplification of Model VII equations compared to lower $I$.

Figure $1 \mathrm{~b}$ shows the change of $\log \gamma_{H^{+}}$versus $I$ between 0.1 and $4 \mathrm{~m}$ for different background electrolyte solutions (i.e., $\mathrm{NaNO}_{3}, \mathrm{NaCl}$, and $\mathrm{NaClO}_{4}$ ) computed according to the SIT equation, where $\varepsilon\left(\mathrm{H}^{+}, \mathrm{NO}_{3}{ }^{-}\right)=0.07 \pm 0.07$ for $\mathrm{NaNO}_{3}, \varepsilon\left(\mathrm{H}^{+}, \mathrm{Cl}^{-}\right)=0.12 \pm 0.01$ for $\mathrm{NaCl}$, and $\varepsilon\left(\mathrm{H}^{+}, \mathrm{ClO}_{4}{ }^{-}\right)=0.14 \pm 0.03$ for $\mathrm{NaClO}_{4}$ electrolytes. The maximum variation in $\log \left(\gamma_{H^{+}}\right)$between 1 and $4 m$, as calculated with SIT, is approximately 0.16 in $\mathrm{NaNO}_{3}, 0.31$ in $\mathrm{NaCl}$ and 0.37 in $\mathrm{NaClO}_{4}$, corresponding to a small dependence of the predicted apparent $\mathrm{pK}_{\mathrm{a}}$ values on $\log \left(\gamma_{H^{+}}\right)$. The slight variation in both $\Psi$ and $\gamma_{H^{+}}$for $1<I<4 m$ is consistent with the experimental observations showing little dependence of apparent $\mathrm{pK}_{\mathrm{a}}$ with $I$ under highly saline conditions (Marinsky et al., 1982; Maes et al., 1992; Kurk and Choppin, 2000). Note that the value of $\gamma_{H^{+}}$ has no direct impact on NICA-Donnan results, because concentrations are involved in the 
equations, and cannot compensate the effects of $I$ on $\Psi_{D}$. Therefore, a slight decrease in $\mathrm{pK}_{\mathrm{a}}(I)$

400 values is predicted with the NICA-Donnan Model when $I$ increases.

To illustrate how PHREEQC-Model VII reproduces acid-base titration data for $\mathrm{I}>1 \mathrm{~m}$,

402 Figure $1 \mathrm{c}$ shows $\mathrm{HA}$ charge versus $\mathrm{pH}_{\mathrm{m}}$ in $0.1,1$ and $3 \mathrm{M}(0.1,1.051,3.503 \mathrm{~m}) \mathrm{NaClO}_{4}$

403 determined by Maes et al. (1992), together with results from Model VII. Experimental data of

404 Marinsky et al. (1982) (in $\mathrm{NaNO}_{3}$ ) and Laszak and Choppin (2001) (in NaCl) with Model VII

405 simulations are shown in Figure S4. For a better illustration, slight adjustment of site densities

406 and $\mathrm{pK}_{\mathrm{a}}$ values was made (see table $\mathrm{S} 1$ ), in order to better reproduce experimental data for $I=0.1$

$407 \mathrm{M}$, and predictions are made for higher $I$. HA charge increases between $I=0.1$ and $1 \mathrm{M}$, which is

408 well predicted. Between $I=1$ and $3 \mathrm{M}$, experimental HA charge decreases, as also predicted by

409 Model VII. This charge decrease is actually related to the use of a $\mathrm{pH}_{\mathrm{m}}$-scale: with a $\mathrm{pH}$-scale

410 (see Fig. S3), Model VII simulations for $I=1$ and $3 \mathrm{M}$ cannot be differentiated (due to the

411 suppression of the electrostatic term), and the difference between the two experimental curves is

412 smaller. Beside small discrepancies between experimental and model results, it can be concluded

413 that Model VII does a relatively good job in predicting HA charging curves in saline conditions. 

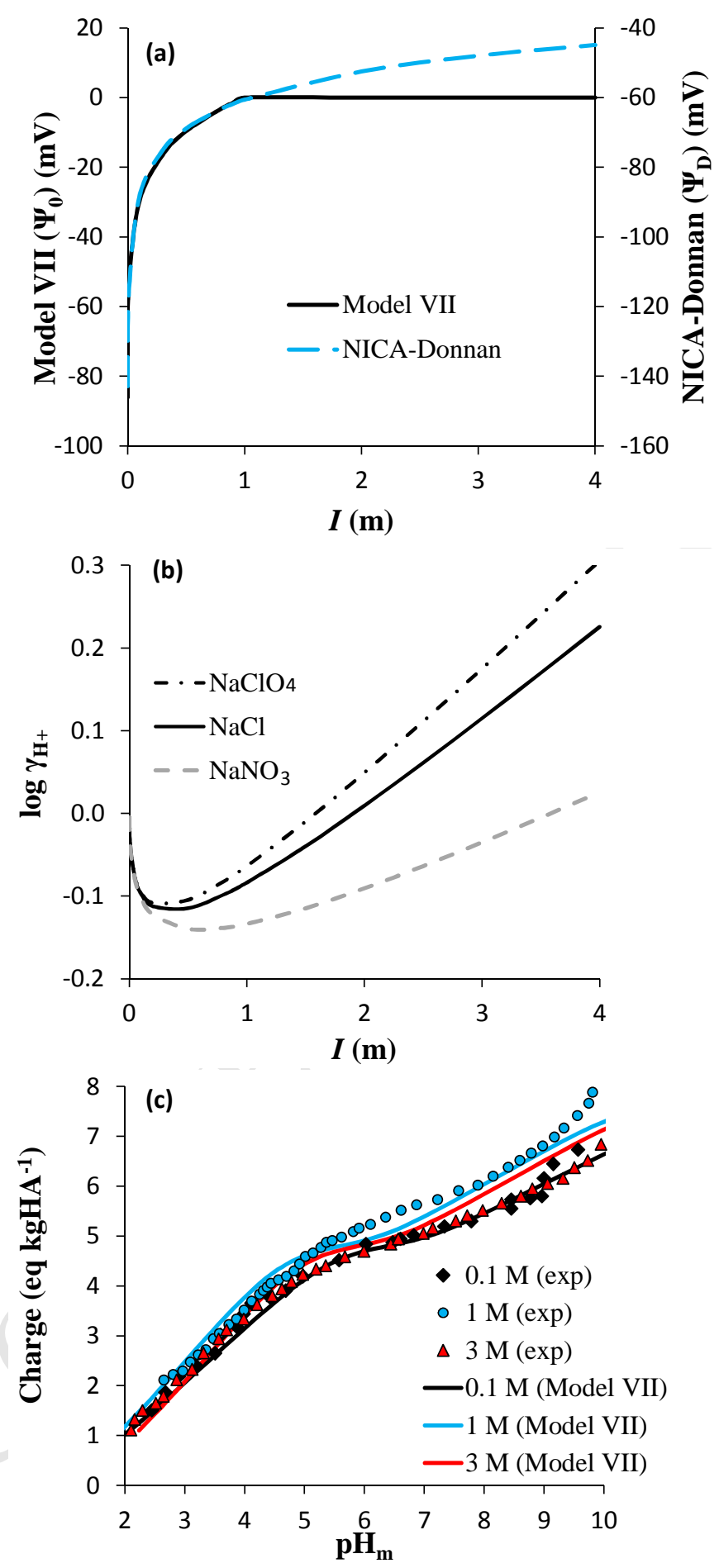

$415 \quad$ Figure 1. (a) Surface potential $\left(\Psi_{0}\right)$ and Donnan potential $\left(\Psi_{D}\right)$ calculated for Model VII and 416 NICA-Donnan, respectively, for $\mathrm{pH}\left(=-\log a_{H^{+}}\right)=5.5$ versus the ionic strength. The y-axis for $417 \Psi_{D}$ is shifted by $60 \mathrm{mV}$ compared with the one of $\Psi_{0}$ to highlight their similar evolution with $I$. 418 (b) Activity coefficient of the proton $\left(\log \gamma_{H^{+}}\right)$versus $I$ in $\mathrm{NaCl}, \mathrm{NaClO}_{4}$ and $\mathrm{NaNO}_{3}$ solutions, 
calculated with SIT. (c) HA charge versus $\mathrm{pH}_{\mathrm{m}}$ in $0.1 \mathrm{M}$ (black curve), $1 \mathrm{M}$ (blue curve), and 3 $\mathrm{M}$ (red curve) $[0.1,1.051,3.503 \mathrm{~m}$, respectively $] \mathrm{NaClO}_{4}$. Points are experimental results of Maes et al. (1992) and lines are results from Model VII. (For interpretation to references to color, the reader is referred to the web version of this article.)

\subsection{Anticipated effects of high ionic strengths on metal ion-HA binding}

As for the proton, apparent metal ion complexation constants with one HA site at a given ionic strength $(\log \mathrm{K}(\mathrm{I})$; data that can be obtained experimentally) can be calculated as follows:

$$
\begin{aligned}
\log { }^{H A} \beta(I)= & \log \frac{\left[M H A^{z_{i}-x}\right]}{\left[M^{z_{i}}+\right]\left[H A^{x-}\right]} \\
& =\log { }^{H A} \beta(I=0)+\log \left(\gamma_{M^{z_{i}}}\right)-z_{i} F \Psi /(R T \ln (10))
\end{aligned}
$$

The term $z_{i} F \Psi /(R T \ln (10))$ leads to substantial $\log { }^{\mathrm{HA}} \beta(\mathrm{I})$ variations for $I<1 \mathrm{~m}$. The amplitude of $\log { }^{\mathrm{HA}} \beta(\mathrm{I})$ variations should increase with increasing metal ion charge $\mathrm{z}_{\mathrm{i}}$. It should also vary with $\Psi$, and hence with the HA charge, Q. Therefore, we can expect that larger $\log { }^{\mathrm{HA}} \beta(\mathrm{I})$ variations would be observed at high $\mathrm{pH}$ and low metal loading compared to low $\mathrm{pH}$ and high metal loading. These three anticipated effects are purely related to HA physico-chemical behavior, which are predicted by Model VII and NICA-Donnan equations and parameters.

Other effects can be anticipated, which are not related to HA behavior but to physicochemical phenomena in solution. As for the proton, $\gamma_{M^{z_{i}}}+$ varies with the ionic strength and the nature of background electrolytes (eq.1), which would directly affect $\log { }^{\mathrm{HA}} \beta(\mathrm{I})$ in eq.16. In the presence of complexing ligands other than $\mathrm{HA}$ (e.g., $\mathrm{OH}^{-}, \mathrm{CO}_{3}{ }^{2-}, \mathrm{Cl}^{-}$, acetate, etc), conditional metal-ligand complexation constants will also evolve with ionic strength, which would affect $\alpha_{M}$ (eq.4). Therefore, we can expect that (i) the presence of ligands will affect trends in $\log { }^{\mathrm{HA}} \beta$ versus $I$ whatever the mathematical expression used for $\log { }^{\mathrm{HA}} \beta$ (see section 2.2) is, and (ii) MHA complexation constants referring to the total dissolved metal ion concentration $\left({ }^{\mathrm{HA}} \beta(\mathrm{M})\right)$ and 
441 to the aquo-ion $\left({ }^{\mathrm{HA}} \beta\left(\mathrm{M}^{\mathrm{Z}+}\right)\right)$ might diverge when varying $I$. For instance, if all conditional metal442 ligand complexation constants increase with increasing $I,{ }^{\mathrm{HA}} \beta(\mathrm{M})$ will decrease, whereas $443{ }^{\mathrm{HA}} \beta\left(\mathrm{M}^{\mathrm{z+}}\right)$ will increase because $\alpha_{M}$ increases with increasing $I$. Prediction of ionic strength effects 444 on $\gamma_{M^{2}}{ }+$ and metal-ligand complexation constants pertain to the thermodynamic database used for 445 aqueous solution (thermodynamic constants and SIT parameters). Therefore, in the presence of 446 ligands other than HA, it is more difficult to test the applicability of Model VII and NICA447 Donnan in saline solutions because ionic strength effects on metal-ligand complexation must be 448 discussed in parallel. In particular, experiments conducted in $\mathrm{NaCl}$ solutions are affected by $\mathrm{M}-\mathrm{Cl}$ 449 complexation, which increases with increasing $\left[\mathrm{Cl}^{-}\right]$, and consequently, the conditional $\mathrm{M}-\mathrm{Cl}$ 450 complexation constants also evolve with $I$. For this reason, metal ion-HA binding data measured 451 in $\mathrm{NaClO}_{4}$ are initially discussed below (i.e., section 3.3), followed by data collected in $\mathrm{NaCl}$ 452 background electrolyte solutions (section 3.4).

\subsection{Cation-HA complexation in $\mathrm{NaClO}_{4}$ solutions}

Am(III)/Cm(III). Czerwinski et al. (1996) investigated $\mathrm{Am}^{3+}$ and $\mathrm{Cm}^{3+}$ complexation with $\mathrm{HA}$ at $\mathrm{pH}_{\mathrm{m}}=6$ and in various $I\left(\mathrm{NaClO}_{4}\right.$ electrolyte solution). Because (i) most of the data are available for $\mathrm{Am}^{3+}$ and (ii) $\mathrm{Am}^{3+}$ and $\mathrm{Cm}^{3+}$ are generally considered as chemical analogues, they will not be distinguished and we will only refer to $\mathrm{Am}^{3+}$ for both datasets in this section. The authors interpreted the data according to the CNM. Only those datasets that allow the determination of the $L C$ (i.e., for $I=0.01,0.1,1.05$ and $3.5 \mathrm{~m}$ ) and that are within the applicability of SIT $(I<4 \mathrm{~m})$ are considered in the present study. The original authors provided the complete raw dataset, which are not reproduced herein. The data are plotted in the form of a

463 binding isotherm, [AmHA] (in mol $\mathrm{kg}_{\mathrm{HA}}{ }^{-1}$ ) versus [Am] $]_{\mathrm{tot}, \mathrm{f}}($ in $\mu m$ ), for each $I$ on Figure 2a. Note 464 that the experimental data for $[\mathrm{Am}]_{\mathrm{tot}, \mathrm{f}}>8 \mu \mathrm{m}$, which are only available for 0.1 and $3.5 \mathrm{~m}$, are not 
465 shown for clarity. In addition, the two separate series of experiments in $I=0.01,0.1$ and $1 \mathrm{~m}$ 466 cannot be visually distinguished on Figure $2 \mathrm{a}$. All the isotherms exhibit a plateau at $\sim 1 \mathrm{~mol} \mathrm{~kg}^{-}{ }^{-}$ $467{ }^{1}$. However, a linear decrease of the $L C$ was observed with $\sqrt{I}$. For $I<1 m, \log { }^{\mathrm{HA}} \beta_{\mathrm{LC}}$ was shown 468 to decrease, whereas it increased for $I>1 \mathrm{~m}$, although in all cases the maximum variation in $\log$ $469{ }^{\mathrm{HA}} \beta_{\mathrm{LC}}$ is relatively small. Accordingly, the original authors reported an average value of $\log$ $470{ }^{\mathrm{HA}} \beta_{\mathrm{LC}}=6.24 \pm 0.14$. Below, we test the capabilities of Model VII and NICA-Donnan to predict 471 the effect of the ionic strength on $\log { }^{\mathrm{HA}} \beta_{\mathrm{LC}}$ and $L C$ for data from Czerwinski et al. (1996). To do 472 so, simulations are made with Model VII and NICA-Donnan under the same conditions as those 473 studied by Czerwinski et al. (1996). The model results are then treated using the equations of the 474 CNM.

The results of the simulations with Model VII are shown on Figure 2a, where the measured and simulated Am-HA binding isotherms for various $I$ are compared. Some 477 discrepancies (either underestimation or overestimation of the model) are observed, which we 478 attribute to the use of generic Model VII parameters and will not be further discussed. As 479 observed experimentally, Model VII predicts decreasing Am-HA complexation with increasing I 480 from 0.01 to $1 \mathrm{~m}$. However, unlike the experimental results, Am-HA complexation is predicted to 481 increase as ionic strength increases from $1 \mathrm{~m}$ to $3.5 \mathrm{~m} \mathrm{NaClO}$. Because Model VII is used as a 482 non-electrostatic model $\left(\Psi_{0}=0\right)$ for $I \geq 1 \mathrm{~m}$, the discrepancy between the experimental data and 483 the model results can best be explained by changes in the activity coefficient of $\mathrm{Am}^{3+}$, which 484 increases between 1 and $3.5 \mathrm{~m} \mathrm{NaClO}_{4}$ according to SIT $\left(\varepsilon\left(\mathrm{Am}^{3+}, \mathrm{ClO}_{4}^{-}\right)=0.49 \mathrm{~kg} \mathrm{~mol}{ }^{-1}\right.$; 485 Guillaumont et al., 2003), as anticipated in eq.1 and eq.16. 

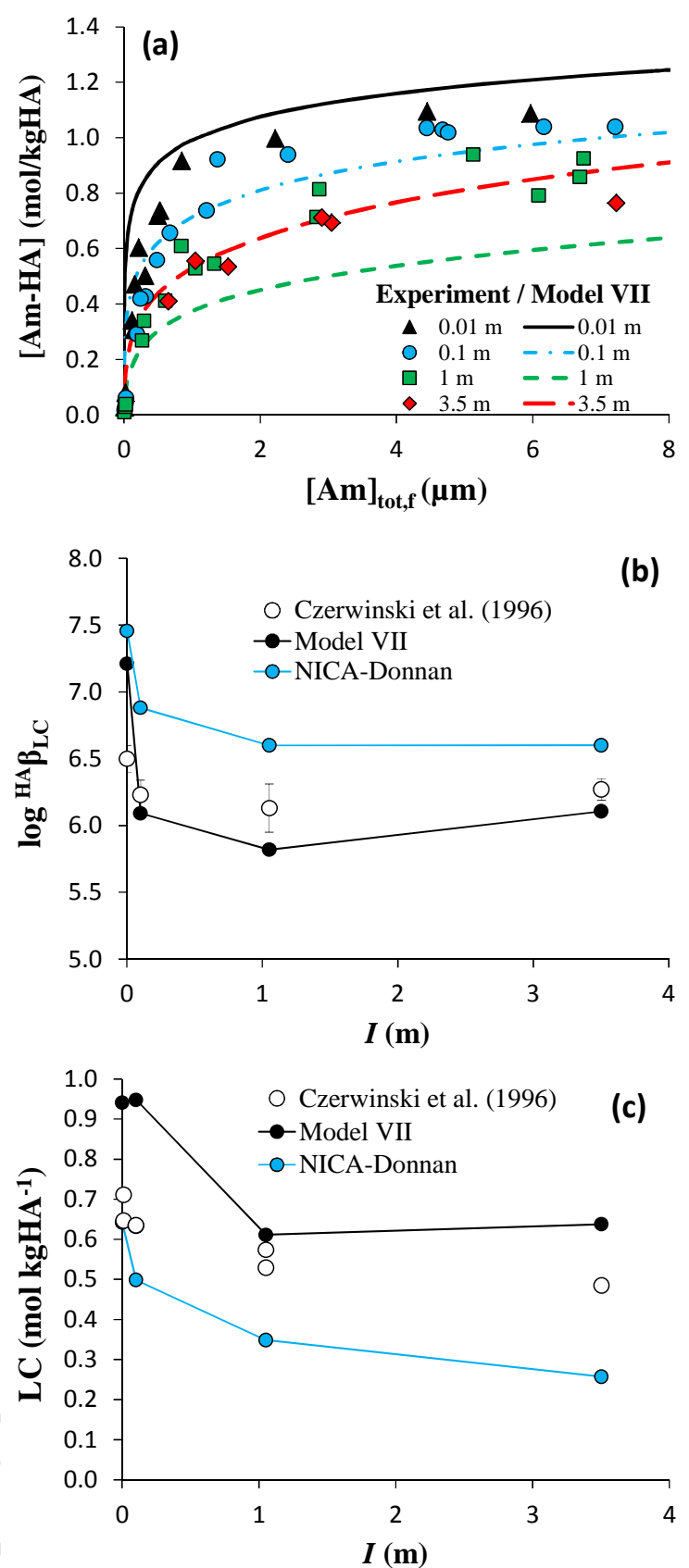

Figure 2. (a) Experimental Am-HA binding isotherms of Czerwinski et al. (1996) for $\mathrm{pH}_{\mathrm{m}}=6$

490 (lines). Experimental (b) $\log { }^{\mathrm{HA}} \beta_{\mathrm{LC}}$ and (c) loading capacity $(L C)$ values for Am compared with 491 Model VII and NICA-Donnan predictions versus $I\left(\mathrm{NaClO}_{4}\right)$ in the experimental conditions of Czerwinski et al. (1996). Experimental error bars are generally smaller than the symbols. 
Although Model VII accounts for HA heterogeneity, over a limited range of $[\mathrm{Am}]_{\text {tot }}$, the model Am-HA isotherm can be approximated by a Langmuir-type isotherm. With this approximation, simulations of Am-HA binding with Model VII are treated according to the CNM equations (given in detail in Czerwinski et al., 1996) to determine ${ }^{\mathrm{HA}} \beta_{\mathrm{LC}}$ and $L C$. The results are plotted, respectively, on Figure 2b and 2c. Within the CNM formalism, Model VII consistently predicts a decrease of both $L C$ and ${ }^{\mathrm{HA}} \beta_{\mathrm{LC}}$ with increasing $I$ from 0.01 and $1 \mathrm{~m}$. The increasing activity of $\mathrm{Am}^{3+}$ between 1 and $3.5 \mathrm{~m} \mathrm{NaClO}_{4}$ leads to an apparent increase of both $L C$ and ${ }^{\mathrm{HA}} \beta_{\mathrm{LC}}$.

Overall, the effect of I predicted by Model VII is consistent with the experimental observations although the variations in $L C$ and ${ }^{\mathrm{HA}} \beta_{\mathrm{LC}}$ values are larger, as already pointed out. The same exercise with NICA-Donnan yields $L C$ and ${ }^{\mathrm{HA}} \beta_{\mathrm{LC}}$ that are also shown in Fig. 2b,c. Although $L C$ and ${ }^{\mathrm{HA}} \beta_{\mathrm{LC}}$ values obtained with NICA-Donnan are lower and higher than the experimental values, respectively, the effect of $I$ is generally well predicted. Unlike Model VII, NICA-Donnan predicts decreasing Am-HA complexation between 1 and $3.5 \mathrm{~m} \mathrm{NaClO}$ because the change in $\gamma_{A m^{3+}}$ cannot compensate for the increase in $\Psi_{D}$ with increasing $I$, according to NICA-Donnan equations (i.e. based on $\mathrm{Am}^{3+}$ concentrations).

$\mathbf{P u}(\mathbf{I V})$. A further example that can be analyzed in the present context is the study by

511 and $0.02<I<3.5 m\left(\mathrm{NaClO}_{4}\right)$. To our knowledge, no $\mathrm{Pu}(\mathrm{IV})$-HA binding parameters are 512 available for NICA-Donnan, and hence, only Model VII can be discussed. The Pu(IV)-HA 513 binding parameters for Model VII are taken from Marsac et al. (2014). Preliminary calculations 514 showed that the formation of polynuclear $\mathrm{Pu}(\mathrm{IV})$ species in the presence of HA (Marsac et al., 515 2014) is not expected for the experimental conditions studied by Szabò et al. (2010). Marsac et al. 516 (2014) used a DLM to account for electrostatic effects when coupling PHREEQC and Model VII, 
517 but the surface area of HA was adjusted to obtain results similar to the original version of Model

518 VII. Here, the same results are obtained when using the CCM to account for electrostatic effects.

519 A modeling approach similar to that used for Am is applied to Pu (Fig. 3). Simulations were 520 performed with Model VII for conditions comparable to those studied by Szabò et al. (2010). The 521 simulated $\mathrm{Pu}-\mathrm{HA}$ binding isotherms for each ionic strength are treated according to the equations 522 given in the latter study to determine the maximal binding capacity of the HA grafted silica gel 523 for $\mathrm{Pu}\left(\mathrm{B}_{\max }\right)$ and $\log { }^{\mathrm{HA}} \beta\left(\mathrm{Pu}^{4+}\right)$. The calculations include the side reaction coefficient for $\mathrm{Pu}(\mathrm{IV})$ 524 (i.e., eq. 4), and the Pu(IV) hydrolysis constants and SIT parameters employed by Szabò et al. 525 (2010), which were originally obtained from Guillaumont et al. (2003). It is important to note that $526 \mathrm{Pu}(\mathrm{IV})$ exhibits strong hydrolysis and that, at $\mathrm{pH}=4, \alpha_{P u}$ varies with $I$ because of ionic strength 527 effects on conditional $\mathrm{Pu}(\mathrm{IV})$ hydrolysis constants.

Simulations with Model VII are compared to the experimental results of Szabò et al.

529 (2010) in Figure 3. The experimental $\mathrm{B}_{\max }$ decreases with increasing $I$ up to $I=0.5 \mathrm{~m}$ and 530 thereafter remains nearly constant up to $I=3.5 \mathrm{~m}$. Model VII predicts little variation in $\mathrm{B}_{\max }$ with 531 ionic strength (i.e., predicted $\mathrm{B}_{\max }$ ranges between $0.52-0.59 \mu \mathrm{mol} \mathrm{g}^{-1}$ ), in contrast to variation of 532 the experimental results $\left(0.16-1.57 \mu \mathrm{mol} \mathrm{g}^{-1}\right)$, and to the modeled $\mathrm{LC}_{\mathrm{Am} \text { (III) }}$ variations. Differences 533 between modeling results for $\mathrm{Am}^{3+}$ and $\mathrm{Pu}^{4+}$ likely arise either from the different metal loadings 534 investigated ([Am(III)-HA] $\leq 1$ and $\left.[\mathrm{Pu}(\mathrm{IV})-\mathrm{HA}] \leq 3 \times 10^{-2} \mathrm{~mol} \mathrm{kgHA}^{-1}\right)$, which has an impact on 535 HA charge, because $\mathrm{Pu}^{4+}$ and $\mathrm{Am}^{3+}$ show different hydrolysis behavior, or because HA grafted 536 silica gel behaves differently than dissolved HA. Presently, we cannot explain the discrepancies 537 between experimental and model results for $\mathrm{Pu}^{4+}$. Nevertheless, the predicted variation in $\mathrm{B}_{\max }$ 538 falls within the experimental range reported by Szabò et al. (2010) so that the impact on the 539 prediction of overall $\mathrm{Pu}^{4+}-\mathrm{HA}$ binding is limited. Experimental and simulated $\log { }^{\mathrm{HA}} \beta\left(\mathrm{Pu}^{4+}\right)$ 540 values are also shown in Figure 3. Generally good agreement is found between the experimental 
541 and predicted $\log { }^{\mathrm{HA}} \beta\left(\mathrm{Pu}^{4+}\right)$ values (Fig. 3), i.e., a decrease up to $I=1 \mathrm{~m}$ followed by an increase

542 up to $3.5 \mathrm{~m}$. The differences are about $\pm 0.5 \log$ units for the stability constant. For $\Psi_{0}=0$ (i.e., for

$543 I>1 \mathrm{~m})$, the increase in $\log { }^{\mathrm{HA}} \beta\left(\mathrm{Pu}^{4+}\right)$ between $I=1$ and $3.5 m$ is due to $\alpha_{P u}$, which increases by

$5440.84 \log$ units over this range of $I$ at $\mathrm{pH}=4$. Indeed, according to the SIT model, $\left[\mathrm{Pu}^{4+}\right]$ decreases

545 with increasing $I$ because of the formation of its hydrolysis products (i.e. the $\sum_{h} \frac{{ }^{*} \beta_{h}}{m_{H^{+}}^{h}}$ term

546 increases in eq. 4). This phenomenon is not observed with $\mathrm{Am}^{3+}$ because its hydrolysis can be 547 neglected at $\mathrm{pH}=6$ and $0<I<4 \mathrm{~m}$.

548

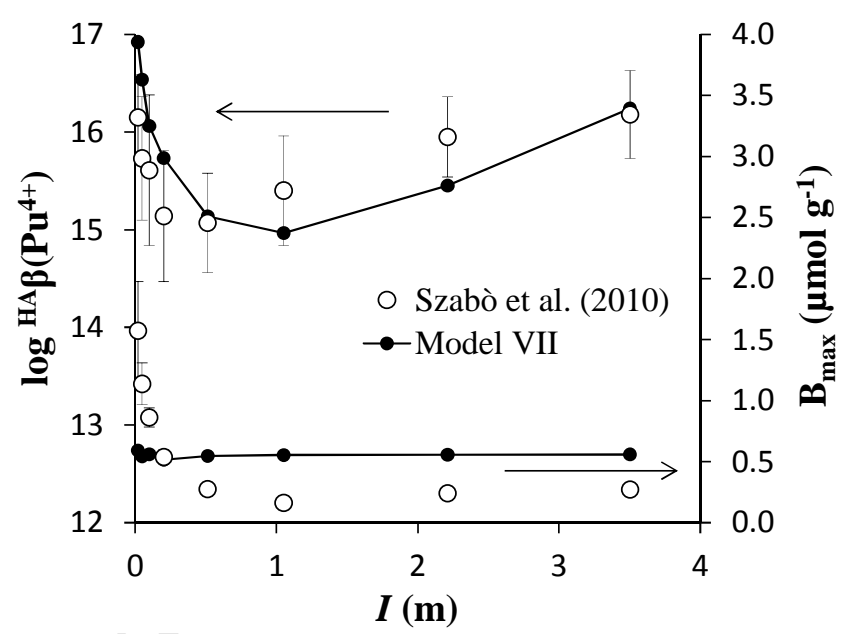

$550 \quad$ Figure 3. Experimental binding capacity $\left(\mathrm{B}_{\max }\right)$ and $\log { }^{\mathrm{HA}} \beta\left(\mathrm{Pu}^{4+}\right)$ values of Szabò et al. (2010)

551 versus $\mathrm{I}\left(\mathrm{NaClO}_{4}\right)$ compared with Model VII predictions. Arrows refer to the $\mathrm{y}$-axis

552 corresponding to the data. Experimental error bars for $\mathrm{B}_{\max }$ are generally smaller than the symbols. 


\subsection{Cation-HA complexation in $\mathrm{NaCl}$ solutions}

In a number of laboratory studies, Choppin and co-workers (Labonne-Wall et al., 1999; Kurk and Choppin, 2000; Laszak and Choppin, 2001; Wall et al., 2002) investigated $\mathrm{U}^{\mathrm{VI}} \mathrm{O}_{2}{ }^{2+}$, $\mathrm{Co}^{2+}, \mathrm{Ni}^{2+}, \mathrm{Ca}^{2+}$ and $\mathrm{Am}^{3+}$ complexation with $\mathrm{HA}$ in $m_{\mathrm{NaCl}}$ solutions by solvent extraction methods in ambient (air) atmosphere. A summary of the experimental conditions is given in Table 1. Only data within the applicability of SIT $(I<4 m)$ are considered in the present study. Although $\mathrm{Cl}^{-}$is clearly a more relevant background anion than $\mathrm{ClO}_{4}{ }^{-}$in the environment, the interpretation of M-HA complexation data obtained for high $m_{\mathrm{NaCl}}$ are more difficult because, unlike $\mathrm{ClO}_{4}{ }^{-}, \mathrm{Cl}^{-}$is a complexing anion, albeit, a weak one. In addition, the Am- and U(VI)-HA experiments were carried out in the presence of $0.01 \mathrm{M}$ acetate buffer. Acetate is known to bind to metal ions and must therefore be taken into account in the calculations (Labonne-Wall et al., 1999; Wall et al., 2002). Finally, unlike the other cations, for $\mathrm{pH}_{\mathrm{m}} \approx 5$ under ambient (air) atmosphere, $\mathrm{UO}_{2}{ }^{2+}$ hydrolysis and complexation by carbonate anions cannot be neglected (Langmuir, 1978; Labonne-Wall et al., 1999). Therefore, M-HA complexation datasets obtained for high $m_{\mathrm{NaCl}}$ are less suitable for testing the applicability of NICA-Donnan and Model VII than experiments conducted in a more inert background electrolyte such as $\mathrm{NaClO}_{4}$. Indeed, it was found that the modeling results discussed below strongly depend on the thermodynamic databases in solution and their respective capabilities to accurately handle the speciation of $\mathrm{Am}^{3+}$, $\mathrm{UO}_{2}{ }^{2+}, \mathrm{Ni}^{2+}, \mathrm{Co}^{2+}$ and $\mathrm{Ca}^{2+}$ in saline solutions, even in the absence of HA. 
Table 1. Summary of the experimental conditions for the M-HA complexation experiments of Wall et al. (2002) $\left(\mathrm{Am}^{3+}\right)$, Labonne-Wall et al. (1999) $\left(\mathrm{UO}_{2}{ }^{2+}\right)$, Kurk and Choppin (2000) $\left(\mathrm{Co}^{2+}\right.$ and $\left.\mathrm{Ni}^{2+}\right)$ and Laszak and Choppin (2001) $\left(\mathrm{Ca}^{2+}\right)$.

\begin{tabular}{cccccc} 
& {$[\mathrm{M}]\left(\mathrm{mol} \mathrm{L}^{-1}\right)$} & {$[\mathrm{HA}]\left(\mathrm{mg} \mathrm{L}^{-1}\right)$} & $m_{N a C l}(\mathrm{~m})$ & $\mathrm{pH}$ & $\mathrm{pH}$ buffer \\
\hline $\mathrm{Am}^{3+}$ & $1 \times 10^{-9}$ & $1-10$ & $0.1-6$ & $5.1\left(\mathrm{pH}_{\mathrm{m}}\right)$ & $10^{-2}$ M acetate \\
$\mathrm{UO}_{2}{ }^{2+}$ & $5.24 \times 10^{-7}$ & $2-10$ & $0.1-6$ & $4.9\left(\mathrm{pH}_{\mathrm{m}}\right)$ & $10^{-2}$ M acetate \\
$\mathrm{Ni}^{2+}$ & $1 \times 10^{-9}$ & $2 \times 10^{-3}-1.6 \times 10^{-2}$ & $0.3-5$ & $6.0\left(\mathrm{pH}_{\text {exp }}\right)$ & No \\
$\mathrm{Co}^{2+}$ & $1 \times 10^{-10}$ & $1.3 \times 10^{-2}-2.2 \times 10^{-1}$ & $0.3-5$ & $6.0\left(\mathrm{pH}_{\text {exp }}\right)$ & No \\
$\mathrm{Ca}^{2+}$ & $1 \times 10^{-8}$ & $0-500$ & $0.1-3$ & $4.5-9.5\left(\mathrm{pH}_{\mathrm{m}}\right)$ & No \\
\hline
\end{tabular}

1999; Kurk and Choppin, 2000; Laszak and Choppin, 2001; Wall et al., 2002). For the studies

listed in Table 1, $\alpha_{H A}$ values were determined for each $\mathrm{pH}$ and $I$ from HA proton titrations for the specific metal ion-HA complexation studies. Because NICA-Donnan and Model VII are able to describe M-HA complexation as a function of the $\mathrm{pH}$, it is more convenient to compare experimental constants that have not been corrected for $\alpha_{H A}$. This can be easily accomplished because all of these studies focused on low metal loadings, where [MHA] can be neglected in eq. 6 (i.e., $\left.[\mathrm{HA}]_{\mathrm{f}} \approx[\mathrm{HA}]_{\mathrm{tot}} \times \alpha_{H A}\right)$. Note that the carboxylic groups of HA were considered responsible for M-HA complexation and only these groups were considered in the calculation of $[\mathrm{HA}]_{\text {tot }}$ (eq. 5-6) (Labonne-Wall et al., 1999; Laszak and Choppin, 2001; Wall et al., 2002). Labonne-Wall et al. (1999) and Wall et al. (2002) reported $1: 1$ and $1: 2 \mathrm{UO}_{2}{ }^{2+} / \mathrm{Am}^{3+}-\mathrm{HA}$ complexation constants. Because, the constants show similar variation with $I$, either for $\mathrm{UO}_{2}{ }^{2+}$ or $\mathrm{Am}^{3+}$, the 1:2 complexes are not discussed here and the simulations are made for the lowest [HA] investigated experimentally (i.e., where the 1:1 complex prevails).

Am(III). Wall et al. (2002) investigated the effect of $\mathrm{NaCl}$ on Am-HA complexation for $\mathrm{pH}_{\mathrm{m}}=5.1$ in $0.01 \mathrm{M}$ acetate buffer. Although constants were corrected for effects of side 
598 reactions, such as the formation of $\mathrm{Am}^{3+}$-acetate complexes (eq. 4), Am-Cl complexation was not 599 taken into account by the original authors. Side reaction corrections for the formation of $\mathrm{Am}^{3+}{ }_{-}$ 600 acetate complexes employed stability constants reported by Moore et al. (1999). Our simulations using Model VII and NICA-Donnan are for the lowest HA concentration $602\left([\mathrm{HA}]=1 \mathrm{mg} \mathrm{L}^{-1}\right)$. Preliminary calculations showed that $\mathrm{Am}-\mathrm{Cl}$ and Am-acetate complexation 603 have no more than a minor impact on the trend in ${ }^{\mathrm{HA}} \mathrm{K}\left(\mathrm{Am}^{3+}\right)$ versus $I$. Experimental and 604 simulated results (now accounting for Am-Cl complexation) are compared on Figure S5. Good 605 prediction of $\mathrm{Am}^{3+}$-HA binding is obtained by both models using generic parameters for $I=0.1$ $606 \mathrm{~m}$, where experimental uncertainty is relatively large, whereas data for all other $I$ are 607 overestimated (see Fig. S5). To better compare experimental and simulated effects of $I$ on $608{ }^{\mathrm{HA}} \mathrm{K}\left(\mathrm{Am}^{3+}\right)$, model results were decreased by $1.5 \log$ unit on Figure $4 \mathrm{a}$. In fact, the adjustment of 609 Am-HA binding parameters would produce the same results. When using the generic Am-HA 610 binding parameters, both models produce similar results, especially for the evolution of $\log \mathrm{K}$ 611 with $I$, as would be expected from the similar variation of $\Psi_{0}$ and $\Psi_{D}$ with $I$ (Fig. 1a). Although 612 model $\log { }^{\mathrm{HA}} \mathrm{K}\left(\mathrm{Am}^{3+}\right)$ values variations with $I$ are not as pronounced as experimental ones, the 613 trend is consistent. Nearly constant $\log { }^{\mathrm{HA}} \mathrm{K}\left(\mathrm{Am}^{3+}\right)$ values are predicted for $I>1 \mathrm{~m}$ by both 614 approaches, which agrees relatively well with the experimental results. Unlike Model VII (where $615 \Psi_{0}=0$ for $I>1 \mathrm{~m}$ ), NICA-Donnan predicts a slight decrease of ${ }^{\mathrm{HA}} \mathrm{K}\left(\mathrm{Am}^{3+}\right)$ for $I>1 \mathrm{~m}$. This is 616 related to the evolution of $\Psi_{D}$ with $I$, and the fact that NICA-Donnan equations do not account for $617 \gamma_{\mathrm{Am}^{3+}}$. Overall, the deviation between both models is small, as expected (Fig. 1a), showing that, 618 by accounting for electrostatic effects, results from Model VII and NICA-Donnan can be 619 extrapolated to highly saline conditions, provided that the specific binding parameters are 620 calibrated for the respective type of HA. 
U(VI). Labonne-Wall et al. (1999) investigated the effect of $I$ on U(VI)-HA complexation

622 for $\mathrm{pH}_{\mathrm{m}}=4.9$ and $0.01 \mathrm{M}$ acetate. $\mathrm{UO}_{2}{ }^{2+}$-acetate complexation constants were taken from Moore

623 et al. (1999) and are also presently used. We simulated the experimental data of Labonne-Wall et

624 al. (1999) using Model VII and NICA-Donnan for the lowest HA concentration ([HA] $=2 \mathrm{mg} \mathrm{L}^{-}$

$625^{1}$ ) and the generic U(VI)-HA binding parameters. As for Am, preliminary tests showed that

626 inclusion or omission of $\mathrm{UO}_{2}{ }^{2+}-\mathrm{Cl}$ complexation did not impact the trend in ${ }^{\mathrm{HA}} \mathrm{K}\left(\mathrm{UO}_{2}{ }^{2+}\right)$ versus $I$.

627 Experimental and simulated results are compared on Figure 4a. The generic U(VI)-HA 628 parameters produce accurate predictions of the ${ }^{\mathrm{HA}} \mathrm{K}\left(\mathrm{UO}_{2}{ }^{2+}\right)$ measured by Labonne-Wall et al. 629 (1999) as well as the evolution of ${ }^{\mathrm{HA}} \mathrm{K}\left(\mathrm{UO}_{2}{ }^{2+}\right)$ with $I$ up to $2 m$. At $I=3 \mathrm{~m}$, a higher ${ }^{\mathrm{HA}} \mathrm{K}\left(\mathrm{UO}_{2}{ }^{2+}\right)$ 630 value than at $I=2 \mathrm{~m}$ was measured, which is also predicted by Model VII. As in the case of $\mathrm{Pu}^{4+}$, 631 where the apparent hydrolysis constants increase with $m_{\mathrm{NaClO}_{4}}$ above $1 \mathrm{~m}$, this increase in $632{ }^{\mathrm{HA}} \mathrm{K}\left(\mathrm{UO}_{2}{ }^{2+}\right)$ is driven by $\alpha_{U(V I)}$. Similar conclusions can be made with NICA-Donnan, except a 633 smaller re-increase in ${ }^{\mathrm{HA}} \mathrm{K}\left(\mathrm{UO}_{2}{ }^{2+}\right)$ that was observed with increasing $I$, as seen and explained for $634 \mathrm{Am}^{3+}$. Interestingly, in agreement with the experimental data, Model VII and NICA-Donnan 635 predict a more pronounced decrease in ${ }^{\mathrm{HA}} \mathrm{K}\left(\mathrm{Am}^{3+}\right)$ than for ${ }^{\mathrm{HA}} \mathrm{K}\left(\mathrm{UO}_{2}{ }^{2+}\right)$ when $I$ increases from 0 636 to $1 \mathrm{~m}$. This feature is driven by the Boltzman factor (eq. 9), which involves the net charge of the 637 cation (i.e. +3 versus +2 , respectively) for $\mathrm{Am}(\mathrm{III})$ and $\mathrm{U}(\mathrm{VI})$. 

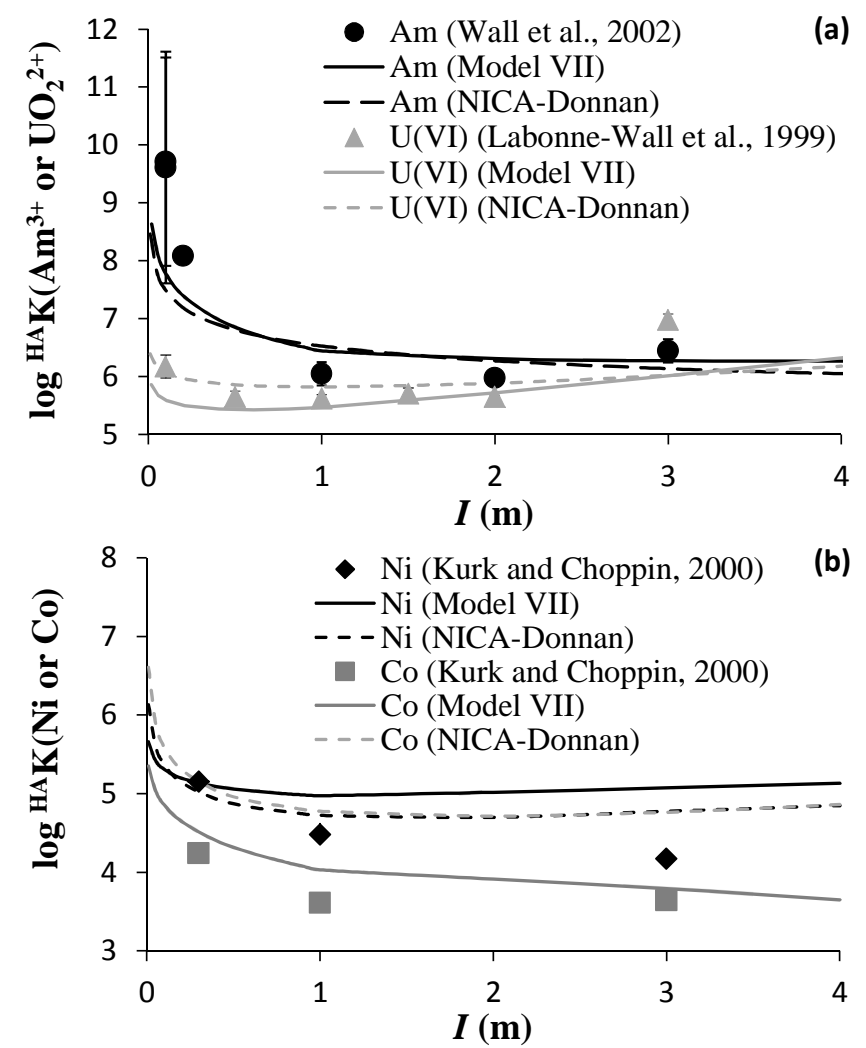

$640 \quad$ Figure 4. (a) Apparent Am-HA and U(VI)-HA complexation constants (Wall et al., 2002;

641 Labonne-Wall et al., 1999) versus $I(\mathrm{NaCl})$ for $\mathrm{pH}_{\mathrm{m}}=5.1$ and 4.9, respectively. (b) Apparent M-

642 HA complexation constants $\left(\mathrm{M}=\mathrm{Ni}^{2+}\right.$ or $\mathrm{Co}^{2+}$, Kurk and Choppin, 2000) versus $I(\mathrm{NaCl})$ for

$643 \mathrm{pH}_{\mathrm{exp}}=6$. For both figures, lines are predictions by Model VII (full line) and NICA-Donnan

644 (dashed lines) using the generic parameters (but shifted down for the case of Am-HA, see text for

Co(II)/Ni(II). Kurk and Choppin (2000) investigated the effect of $I$ on Co- and Ni-HA

648 complexation. Unlike $\mathrm{Am}$ and $\mathrm{U}(\mathrm{VI})$, with data obtained for constant $\mathrm{pH}_{\mathrm{m}}$, Co and $\mathrm{Ni}$ data are

649 reported for constant $\mathrm{pH}_{\mathrm{exp}}=6$ by Kurk and Choppin (2000), noting that the deviation between

$650 \mathrm{pH}_{\mathrm{exp}}$ and $\mathrm{pH}_{\mathrm{m}}$ increases with increasing $I$. For example, for $\mathrm{pH}_{\exp }=6$ and $I=4 \mathrm{~m}$, and with the

651 calibration provided by the original authors, the corresponding $\mathrm{pH}_{\mathrm{m}}$ value is 6.95 . The originally

652 reported constants were not corrected for side reactions. Again, our simulations using Model VII 
653

654

655

656

657

658

659

660

661

662

663

664

665

666

667

668

669

670

671

672

673

674

675

676

and NICA-Donnan were conducted using the lowest HA concentrations reported by Kurk and Choppin (i.e., $[\mathrm{HA}]=1.3 \times 10^{-2} \mathrm{mg} \mathrm{L}^{-1}$ for $\mathrm{Co}$; $[\mathrm{HA}]=2 \times 10^{-3} \mathrm{mg} \mathrm{L}^{-1}$ for $\mathrm{Ni}$ ).

Experimental and simulated results are compared on Figure $4 \mathrm{~b}$. With the generic $\mathrm{Co} / \mathrm{Ni}$ -

HA parameters, Model VII overestimates $\mathrm{Co} / \mathrm{Ni}-\mathrm{HA}$ complexation by 1 log unit in the worst case (i.e., for ${ }^{\mathrm{HA}} \mathrm{K}(\mathrm{Ni})$ at $I=3 \mathrm{~m}$ ). Model VII consistently predicts a decrease in ${ }^{\mathrm{HA}} \mathrm{K}$ with $I$ increasing from 0.3 to $1 \mathrm{~m}$, whereas for $I>1 \mathrm{~m}$, the predicted ${ }^{\mathrm{HA}} \mathrm{K}$ for Co and Ni diverge. Although $\mathrm{pH}_{\mathrm{m}}$ increases by 0.6 units (for constant $\mathrm{pH}_{\mathrm{exp}}$ ) between $I=1$ and $3 \mathrm{~m},{ }^{\mathrm{HA}} \mathrm{K}(\mathrm{Ni}$ ) remains almost constant, whereas ${ }^{\mathrm{HA}} \mathrm{K}(\mathrm{Co})$ decreases by 0.2 log units. These variations reflect the complexation of both of these transition metals by $\mathrm{Cl}^{-}$in solution. In the SIT database provided with PHREEQC, only the $\mathrm{NiCl}^{+}$species is included, with $\varepsilon\left(\mathrm{NiCl}^{+} ; \mathrm{Cl}^{-}\right)=0.1$, whereas four $\mathrm{Co}-\mathrm{Cl}$ complexes are considered (i.e., from $\mathrm{CoCl}^{+}$to $\mathrm{CoCl}_{4}{ }^{2-}$ ), all without SIT parameters (i.e. $\varepsilon(\mathrm{i} ; \mathrm{k})=$ 0). In the SIT database provided with Visual MINTEQ, Co- and Ni-Cl complexation are described similarly and NICA-Donnan predicts the same trend in ${ }^{\mathrm{HA}} \mathrm{K}(\mathrm{Ni})$ and ${ }^{\mathrm{HA}} \mathrm{K}(\mathrm{Co})$ versus $I$. The reliability of the thermodynamic aqueous databases is beyond the scope of the present paper. Nonetheless, despite the potential uncertainties in the databases, overall, the predicted effect of $I$ is relatively small above $1 \mathrm{~m}$ for both $\mathrm{Ni}$ and $\mathrm{Co}$, in agreement with the experimental results.

Ca(II). Figure 5 shows ${ }^{\mathrm{HA}} \mathrm{K}\left(\mathrm{Ca}^{2+}\right)$ measured by Laszak and Choppin (2001) for $m_{N a C l}=$ $0.1,1$ and $3 m$ at various $\mathrm{pH}_{\mathrm{m}}$ under ambient atmosphere. The originally reported constants were corrected for side reactions (including $\mathrm{Ca}$ complexation to chloride and carbonate). Simulations are made with Model VII and NICA-Donnan for $100 \mathrm{mg} \mathrm{L}^{-1} \mathrm{HA}$ using the generic Ca-HA binding parameters and compared to experimental $\log { }^{\mathrm{HA}} \mathrm{K}\left(\mathrm{Ca}^{2+}\right)$ versus $\mathrm{pH}_{\mathrm{m}}$ for $I=0.1$ and $3 \mathrm{~m}$ $(\mathrm{NaCl})$ in Figure 5. Simulations with Model VII for $I=1 \mathrm{~m}$ do not significantly differ from $I=3$ $m$ and consequently are not shown. Experimentally, ${ }^{\mathrm{HA}} \mathrm{K}\left(\mathrm{Ca}^{2+}\right)$ increases with $\mathrm{pH}_{\mathrm{m}}$ and decreases with increasing $I$, as for the other cations investigated. Both Model VII (Fig. 5a) and NICA- 
677 Donnan do a relatively good job at predicting these trends, although the measured effect of $I$ is

678 weaker between 0.1 and $1 \mathrm{~m}$, and $\log { }^{\mathrm{HA}} \mathrm{K}\left(\mathrm{Ca}^{2+}\right)$ are not predicted to evolve substantially for $I$

679 between 1 and $3 m$ with Model VII. Interestingly, the measured effect of $I$ appears more 680 pronounced for $\mathrm{pH}_{\mathrm{m}} \approx 9$ than for $\mathrm{pH}_{\mathrm{m}} \approx 6.5$, which is indeed predicted by both models as 681 anticipated (eq.16). According to the models, the larger negative charge of HA ( $Q$ being 682 proportional to $\Psi_{0}$ or $\Psi_{D}$ ) at high $\mathrm{pH}$ is responsible for the larger ionic strength dependence of $683{ }^{\mathrm{HA}} \mathrm{K}\left(\mathrm{Ca}^{2+}\right)$.

684 To summarize, beside the deviations between experimental and simulated results that are 685 directly related to the parameterization of $\mathrm{Am}^{3+} / \mathrm{UO}_{2}{ }^{2+} / \mathrm{Co}^{2+} / \mathrm{Ni}^{2+} / \mathrm{Ca}^{2+}-\mathrm{HA}$ complexation for a 686 specific type of HA, the generally observed $\log { }^{\mathrm{HA}} \mathrm{K}\left(\mathrm{M}^{\mathrm{z+}}\right)$ dependence with $I$ is relatively well 687 predicted at low metal ion concentration by simply suppressing the electrostatic term in Model 688 VII for $I>1 \mathrm{~m}$. The NICA-Donnan model shows very similar results without the need to modify 689 the model. More experimental results are required, however, to parameterize these models at high $690 I$ and to test the relevance of additional corrections at high $I$ to explain the noted discrepancies, 691 which would make the models more complex. More specifically, complexation studies in non692 complexing background electrolyte (e.g., $\mathrm{NaClO}_{4}$ ) in the absence of pH-buffer (e.g., without 693 acetate) and under inert atmosphere (i.e., in the absence of carbonate) are recommended. 

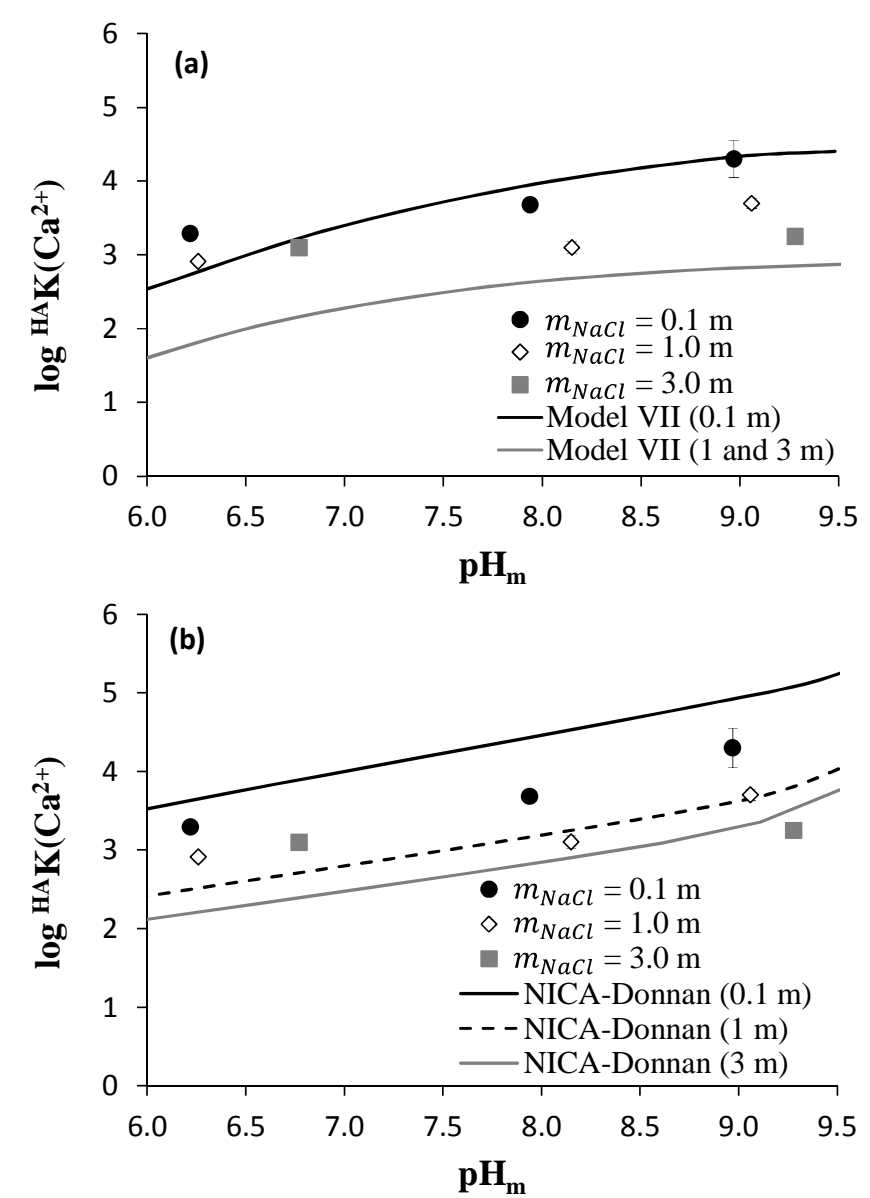

695 Figure 5. Experimental apparent $\mathrm{Ca}^{2+}-\mathrm{HA}$ complexation constants versus $\mathrm{pH}_{\mathrm{m}}$ for $I=0.1,1$ and $6963 \mathrm{~m} \mathrm{NaCl}$ (Laszak and Choppin, 2001) compared with (a) Model VII (simulated curves for $I=1$ 697 and $3 \mathrm{~m} \mathrm{NaCl}$ overlap) and (b) NICA-Donnan predictions. Experimental error bars are commonly smaller than the symbols on all three figures.

\subsection{Metal ion-HA complexation using SIT}

To apply simple models such as the PM or the CNM to various ionic strength solutions,

702 they must include the activities of the aqueous species. According to equations 1 and 3, when all

703 physico-chemical conditions are kept constant except $I$ (pH, T, total metal ion concentration), the

704 value of $\log \beta$ (i.e. $\log { }^{\mathrm{HA}} \mathrm{K}, \log { }^{\mathrm{HA}} \beta_{\alpha}$, or $\log { }^{\mathrm{HA}} \beta_{\mathrm{LC}}$ ) can be extrapolated to $I=0$ ( $\left.\log \beta_{0}\right)$ using:

$$
\log \beta=\log \beta_{0}-\Delta z^{2} \times D-\Delta \varepsilon \times I
$$


For $1: 1$ complexes between a metal ion $\left(\mathrm{M}^{\mathrm{z}}\right)$ and a simple ligand $\left(\mathrm{L}^{\mathrm{y}}\right), \Delta \varepsilon=\varepsilon\left(\mathrm{ML}^{\mathrm{y}+\mathrm{z}}, \mathrm{k}\right)-\varepsilon\left(\mathrm{M}^{\mathrm{z}}, \mathrm{k}\right)-$

$706 \varepsilon\left(\mathrm{L}^{\mathrm{y}}, \mathrm{k}\right)$, and $\Delta \mathrm{z}^{2}=(\mathrm{z}+\mathrm{y})^{2}-\mathrm{z}^{2}-\mathrm{y}^{2}$. Due to the complexity of HA, $\Delta \mathrm{z}^{2}$ and $\Delta \varepsilon$ become adjustable

707 parameters of unclear physical meaning (Czerwinski et al., 1996; Szabò et al., 2010).

Comparing Fig. $2 \mathrm{~b}$ and Fig. $4 \mathrm{a}$, the effect of $I$ on Am-HA complexation appears to differ

709

710

711

712

713 between the studies of Wall et al. (2002) and Czerwinski et al. (1996), but it is difficult to directly compare the original datasets because: (i) the thermodynamic constants refer to different models; (ii) $\mathrm{pH}_{\mathrm{m}}$ differs by one unit; and (iii) the metal loading differs by 3 orders of magnitude. As in Figure $4 \mathrm{a}$ for the $\log { }^{\mathrm{HA}} \mathrm{K}$ values reported by Wall et al. (2002), $\log { }^{\mathrm{HA}} \beta_{\mathrm{LC}}$ values determined by Czerwinski et al. (1996) are recalculated to $\log { }^{\mathrm{HA}} \mathrm{K}$ values using the $L C$ values and imposing negligible [AmHA] in eq. 8. The results are shown in Figure 6a. Although Wall et al. (2002) studied Am-HA complexation at one $\mathrm{pH}_{\mathrm{m}}$ unit lower than Czerwinski et al. (1996), their $\log { }^{\mathrm{HA}} \mathrm{K}$ values are higher. This can be attributed to the effect of the metal loading. Specifically, at low loading, Am binds to low abundance, strong HA sites, whereas, at high loading, these sites are saturated and Am mainly binds to the more abundant, weaker HA sites (e.g., see Marsac et al., 2010). The effect of $I$ below $1 \mathrm{~m}$ is more pronounced for the dataset of Wall et al. (2002), which would lead to different SIT parameters $\left(\Delta \mathrm{z}^{2}\right.$ and $\left.\Delta \varepsilon\right)$ in eq. 17. Therefore, it is difficult to confidently apply an ionic strength correction for cation-HA binding constants using simple metal ion-HA binding models.

The different ionic strength effects observed by Wall et al. (2002) and Czerwinski et al. (1996) might also arise from differences in metal loading. As pointed out by Hummel et al. (2000), ionic strength effects tend to vanish at high loadings. To illustrate this, $\log { }^{\mathrm{HA}} \mathrm{K}$ values for Am-HA complexation are calculated using both Model VII and NICA-Donnan for $\mathrm{pH}=5.5,10^{-3}$ $<I<4 \mathrm{~m}(\mathrm{NaCl}), 1 \mathrm{mg} \mathrm{L}^{-1} \mathrm{HA}$, and $[\mathrm{Am}]_{\mathrm{tot}}=10^{-9}$ or $10^{-6} \mathrm{~m}$. The results are normalized to the $\log$ 
${ }^{\mathrm{HA}} \mathrm{K}$ value obtained for $I=1 m$ (i.e. $\left.\log { }^{\mathrm{HA}} \mathrm{K}(I)-\log { }^{\mathrm{HA}} \mathrm{K}(I=1 m)\right)$ and plotted versus $I$ in Figure

6b. Both models indeed predict a more pronounced effect of $I$ on $\log { }^{\mathrm{HA}} \mathrm{K}$ at low loading.
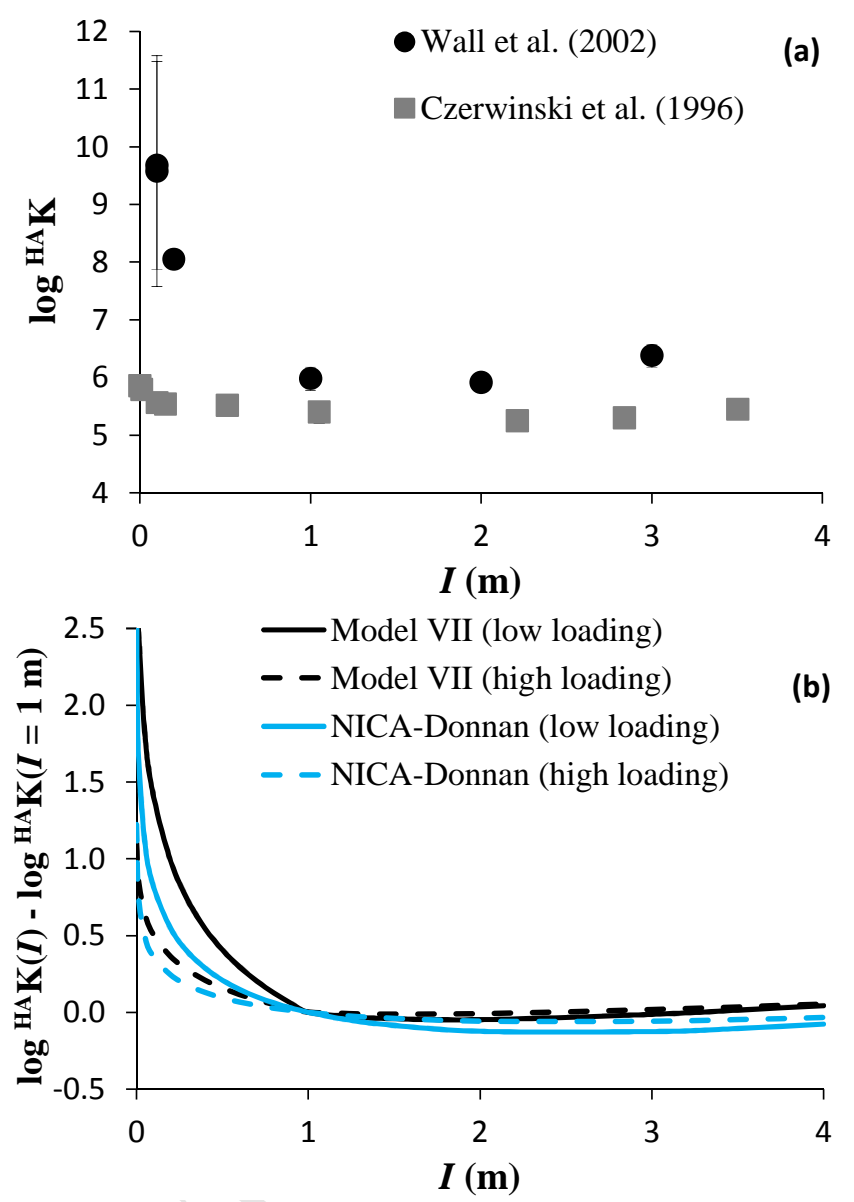

731 Figure 6. (a) Experimentally observed effect of the ionic strength on Am-HA complexation at 732 low (Wall et al., 2002; $\mathrm{pH}_{\mathrm{m}}=5.1 ; \mathrm{NaCl}$ ) and high metal loading (Czerwinski et al., 1996; $\mathrm{pH}_{\mathrm{m}}=$ $\left.7336 ; \mathrm{NaClO}_{4}\right)$. (b) Simulated effect of the ionic strength on Am-HA complexation at low $\left([\mathrm{Am}]_{\text {tot }}=\right.$ $\left.73410^{-9} \mathrm{~m}\right)$ and high metal loading $\left([\mathrm{Am}]_{\text {tot }}=10^{-6} \mathrm{~m}\right)$ with Model VII (black curves) and NICADonnan (blue curves) in $\mathrm{NaCl}$ for a $\mathrm{HA}$ concentration of $1 \mathrm{mg} \mathrm{L}^{-1}$ and $\mathrm{pH}=5.5$. (For interpretation to references to color, the reader is referred to the web version of this article.)

The effect of $I$ on cation-HA complexation is commonly discussed in terms of 739 conformational changes, which make the physical meaning of the values of SIT parameters in the case of humic materials questionable. Multivalent ions are known to bridge between organic 
741 molecules (Kunhi Mouvenchery et al., 2012), and high concentrations of trivalent actinides lead 742 to the aggregation of HA (Lippold et al., 2005). Hence, the different evolution of $\log { }^{\mathrm{HA}} \mathrm{K}$ with $I$ 743 observed by Wall et al. (2002) and Czerwinski et al. (1996) may be partially attributed to the 744 aggregation state (or the conformation) of HA in response to different [Am] to [HA] ratios. In 745 Model VII, conformational changes of HA in response to variations of $I$ are not explicitly treated, 746 except via a change in Donnan volume, which we find to have a negligible effect on M-HA 747 complexation in saline solutions. Because the charging behavior of HA is related to its 748 conformation, such behavior can implicitly be taken into account within the electrostatic term. In 749 NICA-Donnan, the ionic strength directly affects the Donnan volume. However, none of these models includes effects of conformational changes of HA when [Am] $]_{\text {tot }}$ increases (e.g., in the 751 case of NICA-Donnan, $10^{-6} \mathrm{~m}$ of Am would not affect the Donnan volume), by contrast with the 752 more recent Elastic Polyelectrolyte Network electrostatic model (Montenegro et al., 2014). 753 Instead, NICA-Donnan and Model VII explain the less pronounced effect of $I$ at increased 754 loading via the charging behavior of HA. In the experiments of Czerwinski et al. (1996), the 755 observed $L C$ ranges between 50 and $70 \%$ of the PEC. The charge of HA is almost neutralized by 756 Am at the highest $[\mathrm{Am}]_{\text {tot }}$ investigated, which decreases electrostatic effects and flattens the log $757{ }^{\mathrm{HA}} \mathrm{K}$ versus $I$ curve. Therefore, metal loading is an important parameter not only for the 758 determination of apparent metal ion-HA complexation constants for given $\mathrm{pH}$ and $I$ conditions, 759 but also for their extrapolation to various ionic strengths (e.g., with SIT). Unlike $\mathrm{Na}$, with non-specific HA interaction, $\mathrm{Ca}$ and $\mathrm{Mg}$ bind more strongly to HA, and 761 consequently may affect the charge of HA in brines. Furthermore, other metal ions (e.g. Fe(III), $762 \mathrm{Al}(\mathrm{III})$, divalent transition metals) strongly bind to HA in natural conditions (Kinniburgh et al., 763 1999; Pinheiro et al., 2000; Tipping et al., 2002; Gustafsson et al., 2007; Marsac et al., 2012; 764 2013). Hence, the metal loading must be defined on the basis of all cations bound to HA, 
765

766

767

768

769

770

771

772

773

774

775

776

777

778

779

780

781 782

783

784

785

786

787

including $\mathrm{H}^{+}$. Additional cation competition studies should be conducted at high $I$ to improve and homogenize metal ion-HA binding models. As an example, in NICA-Donnan $\mathrm{Ca}^{2+}$ mainly interacts electrostatically with $\mathrm{HA}$ at high $\left[\mathrm{Ca}^{2+}\right]$ (Christl, 2012) whereas it chiefly binds specifically to HA in Model VII. As shown in Figure S6, Model VII predicts larger effects from [Ca] on Am-HA complexation than does NICA-Donnan. For $\mathrm{pH}=5,1 \mathrm{~m} \mathrm{NaCl},[\mathrm{Am}]=10^{-9} \mathrm{~m}$ and $1 \mathrm{mg} \mathrm{L}^{-1} \mathrm{HA}$, between 0 and $1 \mathrm{~m} \mathrm{CaCl}_{2}$, Model VII predicts a decrease of ${ }^{\mathrm{HA}} \mathrm{K}(\mathrm{Am})$ by 1.5 $\log$ units against 0.9 using NICA-Donnan. These results highlight another source of variation and uncertainty for $\Delta \mathrm{z}^{2}$ and $\Delta \varepsilon$ at high [Ca]. Because it is also suggested that $\mathrm{Ca}^{2+}$-HA interaction is purely electrostatic (van Leeuwen and Town, 2016), $\mathrm{Ca}^{2+}$-metal ion competition experiments at high $I$ are required to unravel the role of Ca on metal ion-HA complexation.

As shown above, the ionic strength dependence of ${ }^{\mathrm{HA}} \mathrm{K}\left(\mathrm{Ca}^{2+}\right)$ becomes more pronounced at high $\mathrm{pH}$ because of the higher charge of HA. It appears that $\Delta \mathrm{z}^{2}$ and $\Delta \varepsilon$, when applied to simple models for M-HA complexation, remain conditional parameters, which depend on the $\mathrm{pH}$, the ionic strength, and the composition of the solution, which in turn affects the loading of HA. Therefore, empirical determination of $\Delta \mathrm{z}^{2}$ and $\Delta \varepsilon$ for various conditions requires a large experimental dataset. Because most metal ion-HA binding data at $I>1 \mathrm{~m}$ were obtained at $\mathrm{pH}_{\mathrm{m}} \leq$ 6, data at higher $\mathrm{pH}$ would be necessary to further test the reliability of NICA-Donnan and Model VII.

More generally, the use of non-electrostatic models was recently shown to be particularly suitable for the prediction of metal ion sorption to various types of surfaces in brines, including marine microalgae (Schjif and Herbling, 2010; Zoll and Schjif, 2012), bacteria (Ams et al., 2013), illite and smectite (Schnurr et al., 2015). The present data evaluation suggests that this approach can be extended to humic substances using Model VII. Although NICA-Donnan 
788 remains an electrostatic model in highly saline solution, the almost invariant Donnan potential

789 produces similar ionic strength effects to those observed using Model VII. 


\section{Conclusions}

The applicability of Model VII and NICA-Donnan was tested at high 1:1 background electrolyte concentration $\left(\mathrm{NaCl} / \mathrm{ClO}_{4}\right)$ in combination with SIT $(I<4 m)$. The empirical

793 electrostatic term used in Model VII is related to the constant capacitance model (CCM). A 794 method is proposed to use the CCM in the speciation code PHREEQC, for easier and more consistent implementation of Model VII in this code. The electrostatic term used in this model tends towards zero for $I=1 \mathrm{~m}$, and thus, further metal ion accumulation in the vicinity of HA molecules can be neglected. Consequently, a non-electrostatic model in combination with the binding site definition in Model VII was tested for $I>1 \mathrm{~m}$. The approach simplifies the model under these high ionic strength conditions, whereas NICA-Donnan can be used without modification. Both models do a relatively good job in predicting proton dissociation for HA groups where the apparent $\mathrm{pK}_{\mathrm{a}}$ variations at high $I$ are mainly controlled by the activity coefficient of the proton. The trend in apparent metal ion-HA complexation constants with $I$ is consistent with experimental results for $\mathrm{Am}^{3+}, \mathrm{UO}_{2}{ }^{2+}, \mathrm{Co}^{2+}, \mathrm{Ni}^{2+}, \mathrm{Ca}^{2+}$ and $\mathrm{Pu}^{4+}$, both at low and

804 high metal loading. The maximum metal ion uptake by HA (e.g., the loading capacity) for 805 various conditions is relatively well predicted. Because of the simple approaches used here and 806 due to the limited number of datasets that are available for highly saline solutions, no attempt was 807 made to improve the models in order to eliminate the discrepancies observed in the evolution of 808 apparent complexation constants with $I$. Most of the discrepancies between experiments and 809 predictions with Model VII or NICA-Donnan are related to the specific cation-HA binding

810 parameters used. With appropriately calibrated specific binding parameters for a given type of 811 HA (e.g. a given composition or origin), both models are expected to reliably predict cation-HA 812 binding for a wide range of ionic strengths. 
814 parameters for metal ion-HA complexation was also discussed. When HA is treated as a simple

815 dissolved ligand, the obtained SIT parameters values are difficult to interpret with regards to their 816 specific physical meaning owing to the complexity of HA molecules. It is shown here that the 817 experimentally investigated $\mathrm{pH}$ and metal loading variations have a strong impact on SIT 818 parameters via their effect on the charge of HA. Some effects of $\mathrm{pH}$ and metal loading on cation819 HA complexation are well known, but the present study shows that they imply additional effects 820 related to HA charge, which must be taken into account when extrapolating constants at various 821 ionic strengths. Unlike $\mathrm{Na}$, which only interacts electrostatically with $\mathrm{HA}, \mathrm{Ca}$ or $\mathrm{Mg}$ can bind 822 more strongly to $\mathrm{HA}$. Because, highly saline waters commonly have substantial $\mathrm{Ca}$ or $\mathrm{Mg}$ 823 concentrations, as well as other metal ions, relatively high overall loadings are to be expected. 824 Although Model VII and NICA-Donnan can account for both the metal loading effects and cation 825 competition at $I<1 \mathrm{~m}$, additional cation competition experiments at high ionic strength are 826 required to further validate or improve these models. Nevertheless, we suggest that both models 827 might be used as helpful predictive tools in performance safety assessment even under highly 828 saline conditions.

\section{$830 \quad$ Aknowledgements}

831 This work was financed by the Federal Ministry of Economic Affairs and Energy (Germany) 832 under contracts No. 02E10206 and 02E10961. K. H. Johannesson thanks Michael and Mathilda 833 Cochran for establishing the Cochran Family Professorship in Earth and Environmental Sciences, 834 which provided her financial assistance. We thank three anonymous reviewers and the associate 835 editor (J. P. Gustafsfson) for interesting comments that substantially improved this manuscript. 
860

861

862

863 864

865

866

867

868

869

870

871

872 873

\section{References}

Altmaier M., Metz V., Neck V., Müller R. and Fanghänel Th. (2003) Solid-liquid equilibria of $\mathrm{Mg}(\mathrm{OH})_{2(\mathrm{cr})}$ and $\mathrm{Mg}_{2}(\mathrm{OH})_{3} \mathrm{Cl} \bullet 4 \mathrm{H}_{2} \mathrm{O}_{(\mathrm{cr})}$ in the system Mg-Na-H-OH-Cl- $\mathrm{H}_{2} \mathrm{O}$ at $25{ }^{\circ} \mathrm{C}$. Geochim. Cosmochim. Acta 67, 3595-3601.

Ams D. A., Swanson J. S., Szymanowski J. E. S., Fein J. B., Richmann M. and Reed D. T. (2013) The effect of high ionic strength on neptunium (V) adsorption to a halophilic bacterium. Geochim. Cosmochim. Acta 110, 45-57.

Appelo C. and Postma D. (2005) Geochemistry, groundwater and pollution. second ed. Taylor \& Francis, New York, p. 595.

Benedetti M. F., Milne C. J., Kinniburgh D. G., van Riemsdijk W. H. and Koopal L. K. (1995) Metal-ion binding to humic substances: application of the nonideal competitive adsorption model. Environ. Sci. Technol. 29, 446-457.

Benedetti M. F., van Riemsdijk W. H. and Koopal L. K. (1996) Humic substances considered as a heterogeneous Donnan gel phase. Environ. Sci. Technol. 30, 1805-1813.

Catrouillet C., Davranche M., Dia A., Bouhnik-Le Coz M., Marsac R., Pourret O. and Gruau G. (2014) Geochemical modeling of Fe(II) binding to humic and fulvic acids. Chem. Geol. $372,109-118$.

Catrouillet C., Davranche M., Dia A., Bouhnik-Le Coz M., Pédrot M., Marsac R. and Gruau G. (2015) Thiol groups controls on arsenite binding by organic matter: New experimental and modeling evidence. J. Coll. Int. Sci. 460, 310-320.

Ciavatta, L. (1980). The specific interaction theory in the evaluating ionic equilibria. Ann. Chim. (Rome) 70, 551-562.

Christl I. (2012) Ionic strength- and pH-dependence of calcium binding by terrestrial humic acids. Environ. Chem., 9, 89-96.

Czerwinski K. R., Kim J. I., Rhee D. S. and Buckau G. (1996) Complexation of trivalent actinide ions $\left(\mathrm{Am}^{3+}, \mathrm{Cm}^{3+}\right)$ with humic acid: the effect of ionic strength. Radiochim. Acta $72(4)$, 179-187.

Fritz P. and Frape S. K. (1982). Saline Groundwaters in the Canadian shield - a first overview. Chem. Geol. 36, 179-190.

Grenthe I., Plyasunov A. V. and Spahiu K. (1997) Estimations of Medium Effects on Thermodynamic Data. Chapter IX in "Modeling in aquatic chemistry". OECD Publications, 724 pp. ISBN 92-64-15569-4.

Guillaumont R., Fanghänel Th., Fuger J., Grenthe I., Neck V., Palmer D. A. and Rand M. H. (2003) Update on the Chemical Thermodynamics of Uranium, Neptunium, Plutonium, Americium and Technetium, Mompean, F.J., Domenech-Orti, C., Ben-Said, K., OECD/NEA Data Bank, Eds., vol. 5 of Chemical Thermodynamics, Elsevier, Amsterdam.

Gustafsson J. P. Visual MINTEQ version 3.0. http://vminteq.lwr.kth.se/. Stockholm, Sweden, Octobed 2012. 
Gustafsson J. P., Persson I., Kleja D. B. and van Schaik J. W. J. (2007) Binding of iron(III) to organic soils: EXAFS spectroscopy and chemical equilibrium modeling. Environ. Sci. Technol. 41, 1232-1237.

Hesterberg D., Chou J. W., Hutchison K. J. and Sayers D. E. (2001) Bonding of $\mathrm{Hg}(\mathrm{II})$ to reduced organic, sulfur in humic acid as affected by $\mathrm{S} / \mathrm{Hg}$ ratio. Environ. Sci. Technol. 35, 2741-2745.

Hiemstra T. and van Riemsdijk W. (2006) Biogeochemical speciation of Fe in ocean water. Mar. Chem. 102, 181-197.

Hummel W., Glaus M. A. and Van Loon L. R. (2000) Trace metal-humate interactions. II. The "conservative roof" model and its application. Appl. Geochem. 15, 975-1001.

Kim J. I. and Czerwinski K. R. (1996) Complexation of metal ions with humic acid: metal ion charge neutralisation model. Radiochim. Acta 73, 5-10.

Kinniburgh D. G., Milne C. J., Benedetti M. F., Pinheiro J. P., Filius J., Koopal L. and Van Riemsdijk W. H. (1996) Metal ion binding by humic acid: application of the NICADonnan model. Environ. Sci. Technol. 30, 1687-1698.

Kinniburgh D. G., van Riemsdijk W. H., Koopal L. K., Borkovec M., Benedetti M. F. and Avena M. J. (1999) Ion binding to natural organic matter: competition, heterogeneity, stoichiometry and thermodynamic consistency. Colloid Surf. A 151, 147-166.

Koopal L. K., Saito T., Pinheiro J. P. and van Riemsdijk W.H. (2005) Ion binding to natural organic matter: General considerations and the NICA-Donnan model. Colloids and Surfaces A: Physicochem. Eng. Aspects 265, 40-54.

Kunhi Mouvenchery Y., Kučerík J., Diehl D. and Schaumann G. E. (2012) Cation-mediated cross-linking in natural organic matter: a review. Rev. Environ. Sci. Biotechnol. 11, 4154.

Kurk D. N. and Choppin G. R. (2000) Determination of Co(II) and Ni(II)-humate stability constants at high ionic strength $\mathrm{NaCl}$ solutions. Radiochim. Acta 88, 583-586.

Langmuir D. (1978) Uranium solution-mineral equilibria at low temperatures with applications to sedimentary ore deposits. Geochim. Cosmochim. Acta 42, 547-569.

Labonne-Wall N., Choppin G. R., Lopez C. and Monsallier J.-M. (1999) Interaction of uranyl with humic and fulvic acids at high ionic strength. In: Actinide speciation in high ionic strength media: experimental and modeling approaches to predicting actinide speciation and migration in the subsurface. Eds. Reed D. T., Clark S. B. and Rao L., Plenum Pub., NY, p. 199.

Laszak I. and Choppin G. R. (2001) Interaction study between $\mathrm{Ca}^{2+}$ and humic acids in brine media. Radiochim. Acta 89, 653-659.

Lippold H., Mansel A. and Kupsch H. (2005) Influence of trivalent electrolytes on the humic colloid-borne transport of contaminant metals: competition and flocculation effects. $\mathrm{J}$. Cont. Hydrol. 76, 337-352.

Liu D. J., Bruggeman C. and Maes N. (2008) The influence of natural organic matter on the speciation and solubility of Eu in Boom Clay porewater. Radiochim. Acta 96, 711-720. 
Lützenkirchen J. (1999) The Constant Capacitance Model and Variable Ionic Strength: An Evaluation of Possible Applications and Applicability. J. Coll. Int. Sci. 217, 8-18.

Lützenkirchen J., van Male J., Leermakers F. and Sjöberg S. (2011) Comparison of various models to describe the charge-pH dependence of poly(acrylic acid). J. Chem. Eng. Data $56,1602-1612$.

Maes A., Tits J., Mermans G. and Dierckx A. (1992) Measurement of the potentially available charge and the dissociation behaviour of humic acid from cobaltihexammine adsorption. J. Soil Sci. 43, 669-677.

Marinsky J. A., Gupta S. and Schindler P. (1982) The interaction of $\mathrm{Cu}(\mathrm{II})$ ion with humic acid. J. Coll. Int. Sci. 89, 401-411.

Marquardt C. and Kim J. I. (1998) Complexation of $\mathrm{Np}(\mathrm{V})$ with fulvic acid. Radiochm. Acta 81, 143-148.

Marsac R., Banik N. L., Marquardt C. M. and Kratz J. V. (2014) Stabilization of polynuclear plutonium(IV) species by humic acid. Geochim. Cosmochim. Acta 131, 290-300.

Marsac R., Davranche M., Gruau G. and Dia A. (2010) Metal loading effect on rare earth element binding to humic acid: Experimental and modeling evidence, Geochim. Cosmochim. Acta 74, 1749-1761.

Marsac R., Davranche M., Gruau G., Bouhnik-Le Coz M. and Dia A. (2011) An improved description of the interactions between rare earth elements and humic acids by modeling: PHREEQC-Model VI coupling. Geochim. Cosmochim. Acta 75, 5625-5637.

Marsac R., Davranche M., Gruau G., Dia A. and Bouhnik-Le Coz M. (2012) Aluminium competitive effect on rare earth elements binding to humic acid. Geochim. Cosmochim. Acta 89, 1-9.

Marsac R., Davranche M., Gruau G., Dia A., Pédrot M., Bouhnik-Le Coz M. and Briant N. (2013) Effects of Fe competition on REE binding to humic acid: Origin of REE pattern variability in organic waters. Chem. Geol. 342, 119-127.

Martell A.E. and Hancock R.D. (1996) Metal Complexes in Aqueous Solutions. New York: Kluwer.

Milne C. J., Kinniburgh D. G. and Tipping E. (2001) Generic NICA-Donnan model parameters for proton binding by humic substances. Environ. Sci. Technol. 35, 2049-2059.

Milne C. J., Kinniburgh D. G., Van Riemsdijk W. H. and Tipping E. (2003) Generic NICADonnan model parameters for metal-ion binding by humic substances. Environ. Sci. Technol. 37, 958-971.

Montenegro A. C., Orsetti S. and Molina F. V. (2014) Modelling proton and metal binding to humic substances with the NICA-EPN model. Environ. Chem. 11, 318-332.

Moore R. C., Borkowski M., Bronikowski M. G., Chen J.-F., Pokrovsky O. S., Xia Y. and Choppin G. R. (1999) Thermodynamic modeling of actinide complexation with acetate and lactate at high ionic strength. J. Sol. Chem. 28, 521-531.

Mühlenweg U., Brasser Th. and Hertes U. (1997) Charakterisierung von mineralisierten Tiefengrundwässern in nichtsalinaren Festgesteinen. Report GRS-144, ISBN 3-93199504-6, Gesellschaft für Anlagen- und Reaktorsicherheit (GRS) mbH, Germany. p. 19 
Parkhurst D. L. and Appelo C. A. J. (1999) User's guide to PHREEQC (Version 2) - a computer program for speciation, batch reaction, one-dimensional transport and inverse geochemical calculation. Water-resources Investigation Report 99-4259, USGS, Denver, Colorado, p. 312.

Pinheiro J. P., Mota A. M. and Benedetti M. F. (2000) Effect of aluminum competition on lead and cadmium binding to humic acids at variable ionic strength. Environ. Sci. Technol. 34, 5137-5143.

Pitzer K. S. (1991) Ion interaction approach: theory and data correlation. In: Pitzer, K.S. (Ed.), Activity Coefficients in Electrolyte Solutions. CRC Press, Boca Raton, Florida, pp. 75153.

Rey-Castro C., Lodeiro P., Herrer R. and Sastre De Vicente M. E. (2003) Acid-base properties of brown seaweed biomass considered as a Donnan gel. A model reflecting electrostatic effects and chemical heterogeneity. Environ. Sci. Technol. 37, 5159-5167.

Ringböm A. (1963) Complexation in Analytical Chemistry. Interscience, New York.

Ritchie J. D. and Perdue E.M. (2003) Proton-binding study of standard and reference fulvic acids, humic acids, and natural organic matter. Geochim. Cosmochim. Acta 67, 85-96.

Sasaki T., Kobayashi T., Tagagi I. and Moriyama H. (2008) Discrete fragment model for complex formation of europium(III) with humic acid. J. Nucl. Sci. Technol. 45(8), 718724.

Schijf J. and Ebling A. M. (2010) Investigation of the ionic strength dependence of Ulva lactuca acid functional group pKas by manual alkalimetric titrations. Environ. Sci. Technol. 44, 1644-1649.

Schnurr A., Marsac R., Kupcik T., Rabung T., Lützenkirchen J. and Geckeis H. (2015) Sorption of $\mathrm{Cm}(\mathrm{III})$ and $\mathrm{Eu}(\mathrm{III})$ onto clay minerals under saline conditions: Batch adsorption, Laser-fluorescence spectroscopy and modeling. Geochim. Cosmochim. Acta 151, 192202.

Stockdale A., Tipping E., Hamilton-Taylor J. and Lofts S. (2011) Trace metals in the open oceans: speciation modelling based on humic type ligands. Environ. Chem. 8(3), 304-319.

Szabò G., Guczi J., Reiller P., Miyajima T. and Bulman R. A. (2010) Effect of ionic strength on complexation of $\mathrm{Pu}(\mathrm{IV})$ with humic acid. Radiochim. Acta 98, 13-18.

Tipping E. (1998) Humic ion-binding model VI: an improved description of the interactions of protons and metal ions with humic substances. Aquat. Geochem. 4, 3-48.

Tipping E. and Hurley M. A. (1992) A unifying model of cation binding by humic substances. Geochim. Cosmochim. Acta 56, 3627-3641.

Tipping E., Lofts S. and Sonke J. (2011) Humic ion-binding Model VII: a revised parameterisation of cation-binding by humic substances. Environ. Chem. 8, 225-235.

Tipping E., Rey-Castro C., Bryan S. E. and Hamilton-Taylor J. (2002) Al(III) and Fe(III) binding by humic substances in freshwaters and implications for trace metal speciation. Geochim. Cosmochim. Acta 66, 3211-3224

Torres R. A. and Choppin G. R. (1984) Europium(III) and Americium(III) stability constants with Humic acid. Radiochim. Acta 35(3), 143-148. 
Turner A., Pedroso S. S. and Brown M. T. (2008) Influence of salinity and humic substances on the uptake of trace metals by the marine macroalga, Ulva lactuca: Experimental observations and modelling using WHAM. Mar. Chem. 110, 176-184.

van Dijk H. Z. (1959) Zur Kenntnis der Basenbindung von Huminsäuren. Pflanzenernähr. Düng. Bodenk. 84, 150-155.

van Leeuwen H. P. and Town R. M. (2016) Electric condensation of divalent counterions by humic acid nanoparticles. Environ. Chem. 13, 76-83.

Wall N. A. and Choppin G. R. (2003) Humic acids coagulation: influence of divalent cations. Appl. Geochem. 18, 1573-1582.

Wall N. A., Borkowski M., Chen J.-F. and Choppin G. R. (2002) Complexation of americium with humic, fulvic and citric acids at high ionic strength. Radiochim. Acta 90, 563-568.

Zoll A. M. and Schjif J. (2012) A surface complexation model of YREE sorption on Ulva lactuca in 0.05-5.0 M NaCl solutions. Geochim. Cosmochim. Acta 97, 183-199. 
1010

1011

1012

1013

1014

1015

1016

1017

1018

1019

1020

1021

1022

1023

1024

1025

1026

1027

1028

1029

1030

1031 Figure 4. (a) Apparent Am-HA and U(VI)-HA complexation constants (Wall et al., 2002;

1032 Labonne-Wall et al., 1999) versus $I(\mathrm{NaCl})$ for $\mathrm{pH}_{\mathrm{m}}=5.1$ and 4.9, respectively. (b) Apparent M-

1033 HA complexation constants $\left(\mathrm{M}=\mathrm{Ni}^{2+}\right.$ or $\mathrm{Co}^{2+}$, Kurk and Choppin, 2000) versus $I$ ( $\left.\mathrm{NaCl}\right)$ for

$1034 \mathrm{pH}_{\exp }=6$. For both figures, lines are predictions by Model VII (full line) and NICA-Donnan

1035 (dashed lines) using the generic parameters (but shifted down for the case of Am-HA, see text for

1036

\section{Table and figure captions:}

Table 1. Summary of the experimental conditions for the M-HA complexation experiments of Wall et al. (2002) $\left(\mathrm{Am}^{3+}\right)$, Labonne-Wall et al. (1999) $\left(\mathrm{UO}_{2}{ }^{2+}\right)$, Kurk and Choppin (2000) $\left(\mathrm{Co}^{2+}\right.$ and $\left.\mathrm{Ni}^{2+}\right)$ and Laszak and Choppin (2001) $\left(\mathrm{Ca}^{2+}\right)$.

Figure 1. a) Surface potential $\left(\Psi_{0}\right)$ and Donnan potential $\left(\Psi_{D}\right)$ calculated for Model VII and NICA-Donnan, respectively, for $\mathrm{pH}\left(=-\log a_{H^{+}}\right)=5.5$ versus the ionic strength. The y-axis for $\Psi_{D}$ is shifted by $60 \mathrm{mV}$ compared with the one of $\Psi_{0}$ to highlight their similar evolution with $I$. (b) Activity coefficient of the proton $\left(\log \gamma_{H^{+}}\right)$versus $I$ in $\mathrm{NaCl}, \mathrm{NaClO}_{4}$ and $\mathrm{NaNO}_{3}$ solutions, calculated with SIT. (c) HA charge versus $\mathrm{pH}_{\mathrm{m}}$ in $0.1 \mathrm{M}$ (black curve), $1 \mathrm{M}$ (blue curve), and 3 $\mathrm{M}$ (red curve) $\left[0.1,1.051,3.503 \mathrm{~m}\right.$, respectively] $\mathrm{NaClO}_{4}$. Points are experimental results of Maes et al. (1992) and lines are results from Model VII. (For interpretation to references to color, the reader is referred to the web version of this article.)

Figure 2. (a) Experimental Am-HA binding isotherms of Czerwinski et al. (1996) for $\mathrm{pH}_{\mathrm{m}}=6$ and $m_{\mathrm{NaClO}_{4}}=0.01,0.1,1$ and $3.5 \mathrm{~m}$ (symbols) compared with simulations using Model VII (lines). Experimental (b) $\log { }^{\mathrm{HA}} \beta_{\mathrm{LC}}$ and (c) loading capacity ( $L C$ ) values for Am compared with Model VII and NICA-Donnan predictions versus $I\left(\mathrm{NaClO}_{4}\right)$ in the experimental conditions of Czerwinski et al. (1996). Experimental error bars are generally smaller than the symbols.

Figure 3. Experimental binding capacity $\left(\mathrm{B}_{\max }\right)$ and $\log { }^{\mathrm{HA}} \beta\left(\mathrm{Pu}^{4+}\right)$ values of Szabò et al. (2010) versus I $\left(\mathrm{NaClO}_{4}\right)$ compared with Model VII predictions. Arrows refer to the $\mathrm{y}$-axis corresponding to the data. Experimental error bars for $B_{\max }$ are generally smaller than the symbols. details). Experimental error bars are commonly smaller than the symbols. 
1037 Figure 5. Experimental apparent $\mathrm{Ca}^{2+}$-HA complexation constants versus $\mathrm{pH}_{\mathrm{m}}$ for $I=0.1,1$ and $10383 \mathrm{~m} \mathrm{NaCl}$ (Laszak and Choppin, 2001) compared with (a) Model VII (simulated curves for $I=1$ 1039 and $3 \mathrm{~m} \mathrm{NaCl}$ overlap) and (b) NICA-Donnan predictions. Experimental error bars are commonly 1040 smaller than the symbols on all three figures.

1041 Figure 6. (a) Experimentally observed effect of the ionic strength on Am-HA complexation at 1042 low (Wall et al., 2002; $\left.\mathrm{pH}_{\mathrm{m}}=5.1 ; \mathrm{NaCl}\right)$ and high metal loading $\left(\right.$ Czerwinski et al., 1996; $\mathrm{pH}_{\mathrm{m}}=$

1043 6; $\left.\mathrm{NaClO}_{4}\right)$. (b) Simulated effect of the ionic strength on Am-HA complexation at low $\left([\mathrm{Am}]_{\mathrm{tot}}=\right.$ $\left.104410^{-9} \mathrm{~m}\right)$ and high metal loading $\left([\mathrm{Am}]_{\mathrm{tot}}=10^{-6} \mathrm{~m}\right)$ with Model VII (black curves) and NICA1045 Donnan (blue curves) in $\mathrm{NaCl}$ for a $\mathrm{HA}$ concentration of $1 \mathrm{mg} \mathrm{L}^{-1}$ and $\mathrm{pH}=5.5$. (For 1046 interpretation to references to color, the reader is referred to the web version of this article.)

1047

1048

1049

\begin{tabular}{cccccc} 
& {$[\mathrm{M}]\left(\mathrm{mol} \mathrm{L}^{-1}\right)$} & {$[\mathrm{HA}]\left(\mathrm{mg} \mathrm{L}^{-1}\right)$} & $m_{N a C l}(\mathrm{~m})$ & $\mathrm{pH}$ & $\mathrm{pH}$ buffer \\
\hline $\mathrm{Am}^{3+}$ & $1 \times 10^{-9}$ & $1-10$ & $0.1-6$ & $5.1\left(\mathrm{pH}_{\mathrm{m}}\right)$ & $10^{-2}$ M acetate \\
$\mathrm{UO}_{2}{ }^{2+}$ & $5.24 \times 10^{-7}$ & $2-10$ & $0.1-6$ & $4.9\left(\mathrm{pH}_{\mathrm{m}}\right)$ & $10^{-2}$ M acetate \\
$\mathrm{Ni}^{2+}$ & $1 \times 10^{-9}$ & $2 \times 10^{-3}-1.6 \times 10^{-2}$ & $0.3-5$ & $6.0\left(\mathrm{pH}_{\text {exp }}\right)$ & No \\
$\mathrm{Co}^{2+}$ & $1 \times 10^{-10}$ & $1.3 \times 10^{-2}-2.2 \times 10^{-1}$ & $0.3-5$ & $6.0\left(\mathrm{pH}_{\text {exp }}\right)$ & No \\
$\mathrm{Ca}^{2+}$ & $1 \times 10^{-8}$ & $0-500$ & $0.1-3$ & $4.5-9.5\left(\mathrm{pH}_{\mathrm{m}}\right)$ & No \\
\hline
\end{tabular}



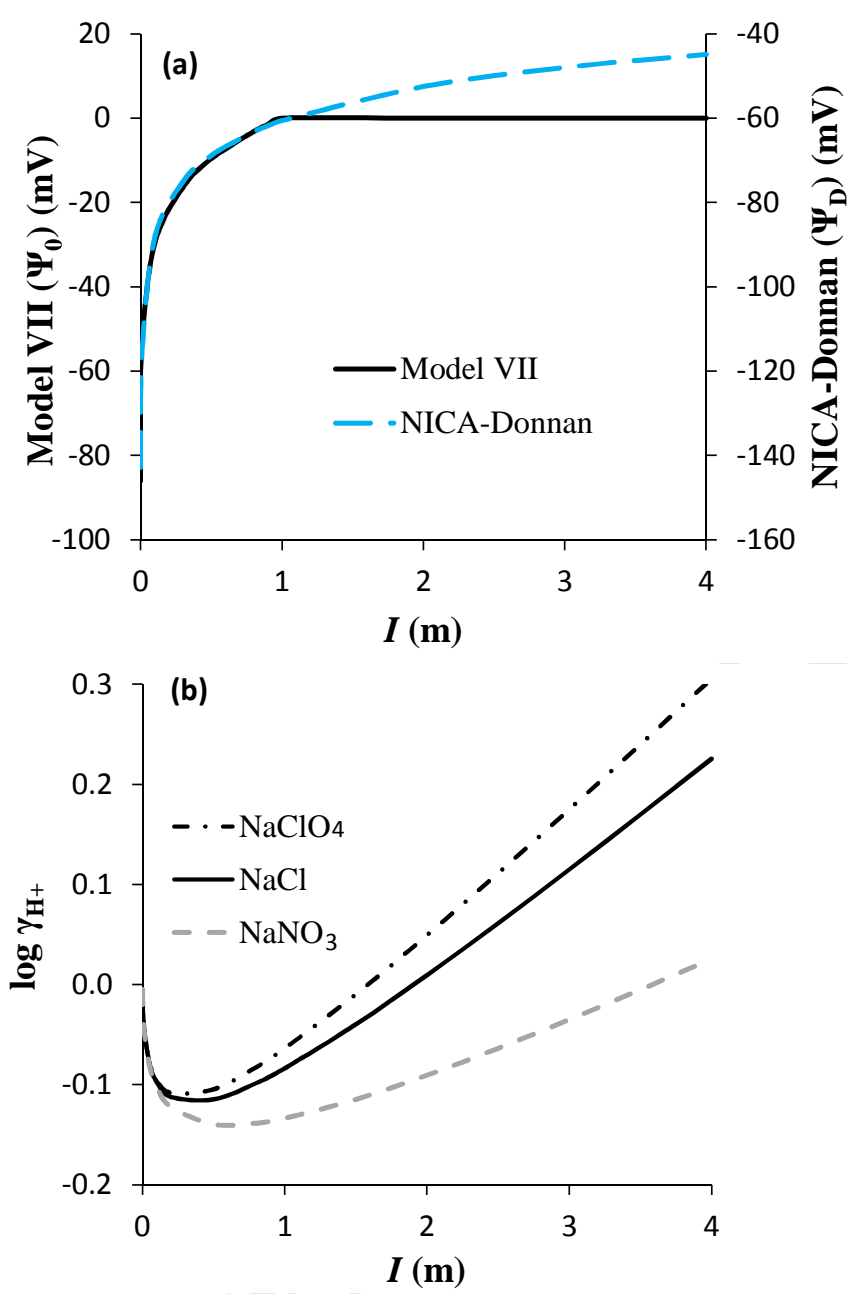

1053

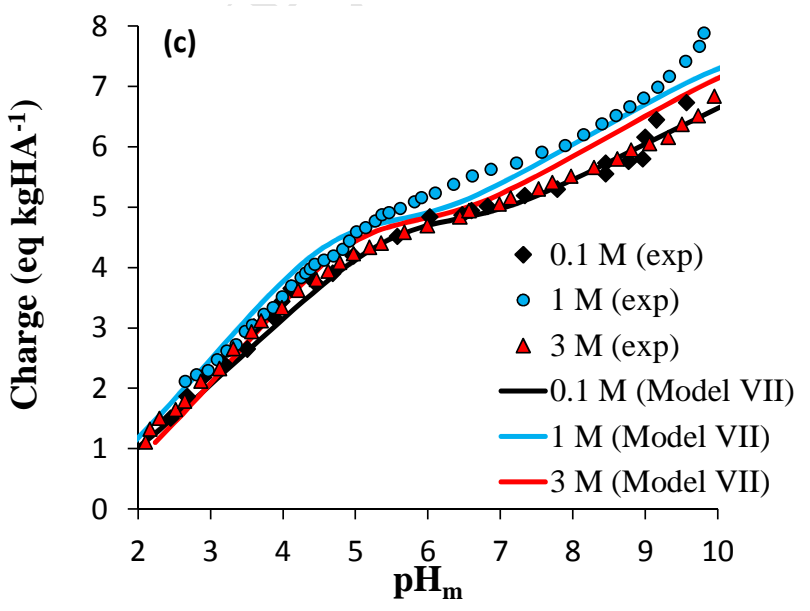

1054

1055

Figure 1 

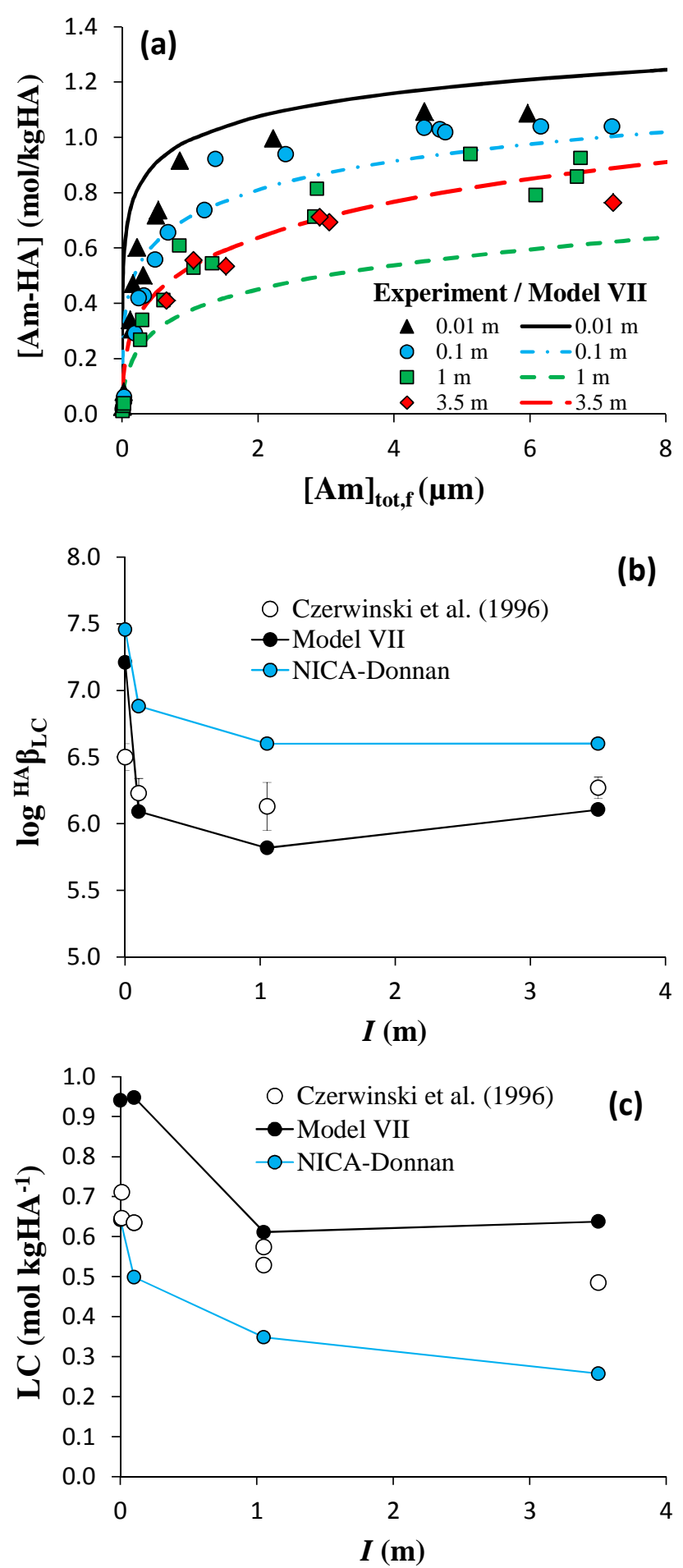

1056

1057

1058

1059

1060

Figure 2

1061 
1062

1063

1064

1065

1066
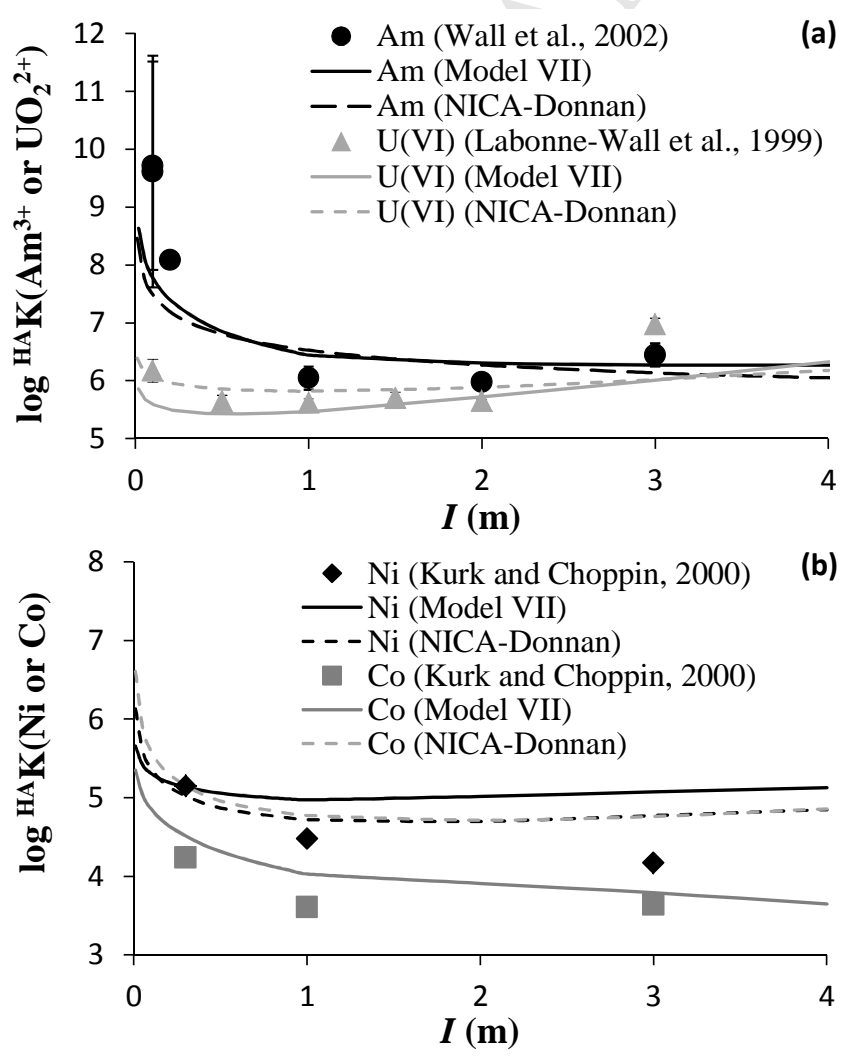

Figure 3

(a)

)

1067

1068

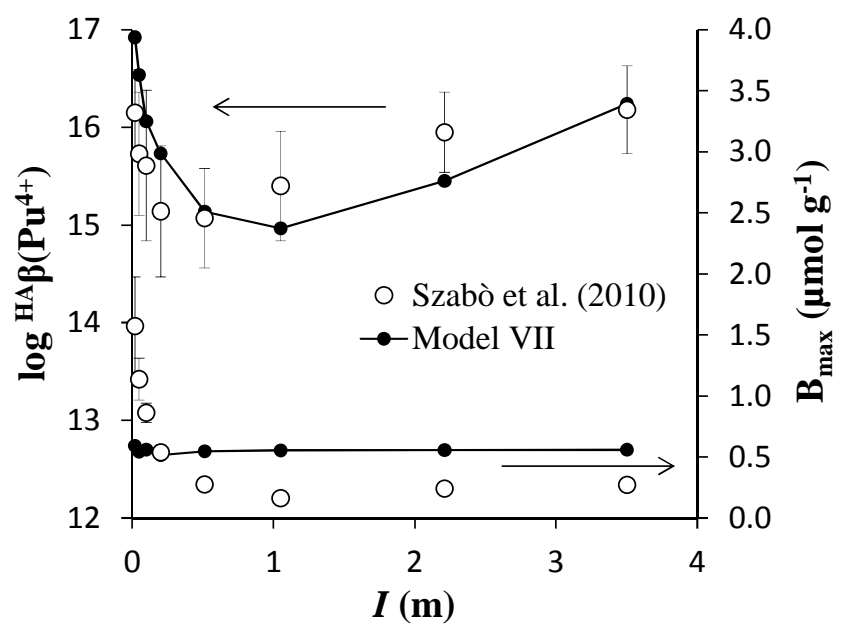


1069
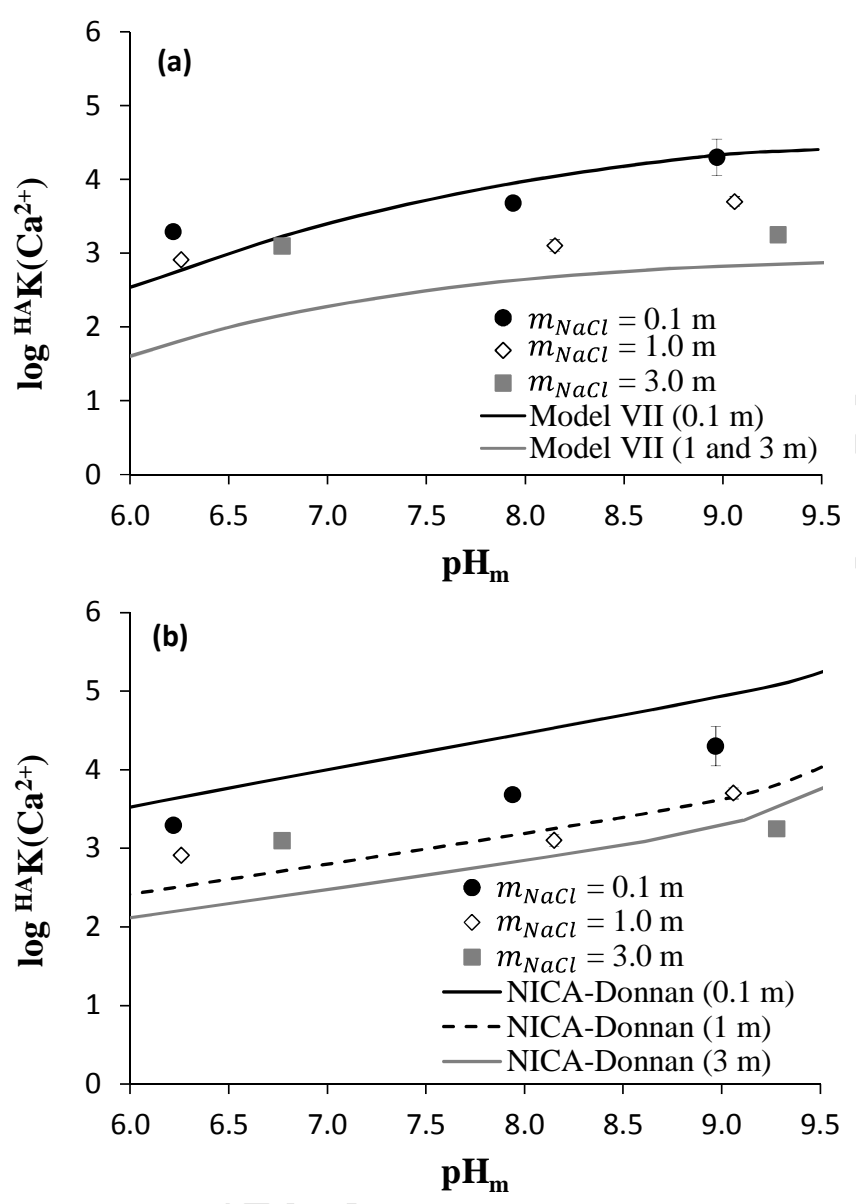

1071

1072

Figure 5

1073 
1074
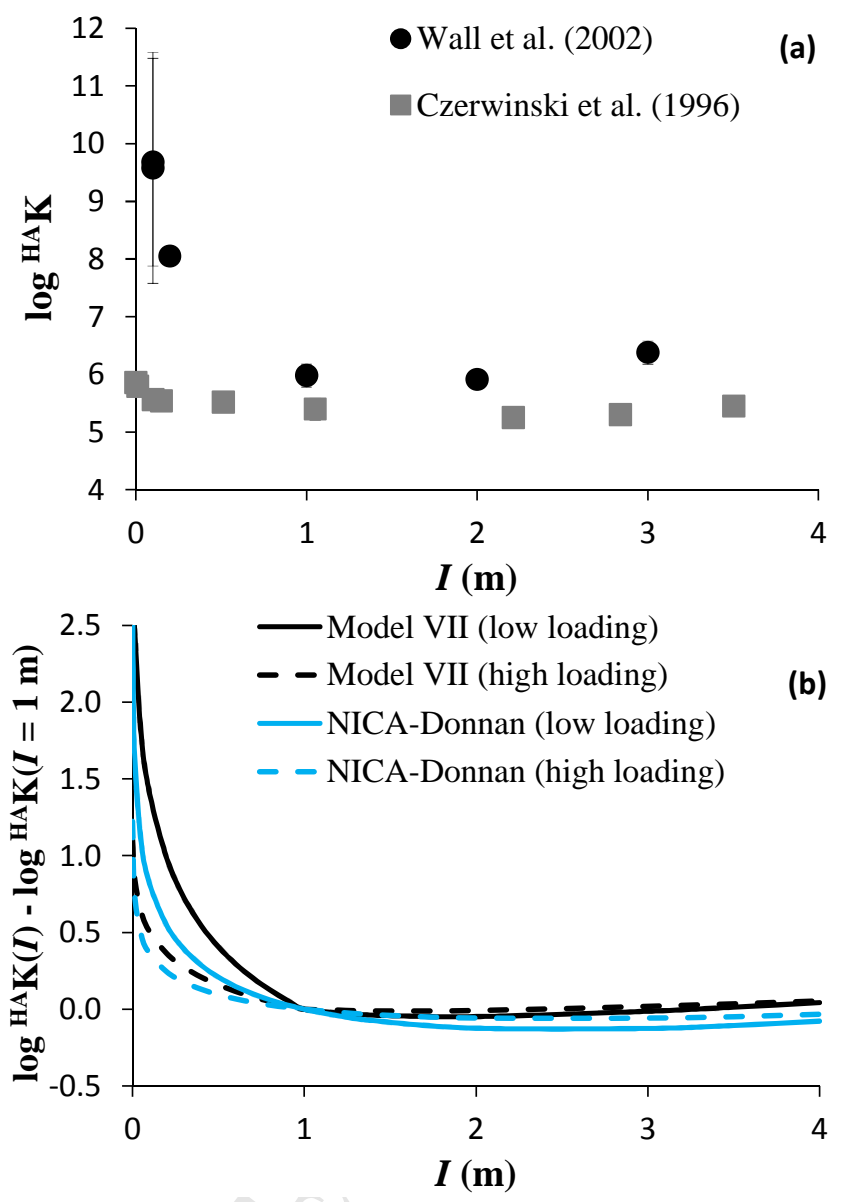

1076

Figure 6 